\title{
Nasal Coarticulation in Bininj Kunwok: An Aerodynamic Analysis
}

\author{
Hywel Stoakes ${ }^{1}$, Janet Fletcher ${ }^{1}$, Andrew Butcher ${ }^{2}$ \\ ${ }^{1}$ The University of Melbourne, ${ }^{2}$ Flinders University \\ hstoakes@unimelb.edu.au, j.fletcher@unimelb.edu.au, andy.butcher@flinders.edu.au
}

Revised manuscript submitted to the Journal of the International Phonetic Association

April $30^{\text {th }}, 2018$

\begin{abstract}
:
Bininj Kunwok (BKw), a language with complex polysynthetic morphology spoken in Northern Australia, is thought to restrict the degree of anticipatory nasalization, suggested in an aerodynamic and acoustic analysis by Butcher (1999). Sonorant consonants are very common in Australian languages generally, and the phonological pattern most prevalent is one that has nasals matched to stops at least five places of articulation and very few restrictions on the position within a word. This study uses aerodynamic measurements of speech to investigate the patterns of nasalization to gain insight into nasal articulation in Bininj Kunwok and possibly in Australian languages more generally. It explores the role of nasal coarticulation in ensuring language comprehensibility, a key question in phonetics research (Harrington et al., 2013). Nasal aerodynamics is measured in intervocalic, word medial nasals in the speech of five female speakers of BKw. This study reports patterns of coarticulation using a Smoothing Spline Analysis of Variance (SSANOVA) and Functional Data Analysis using b-splines (Ramsay et al., 2017). Results show that in a VNV sequence there is very little anticipatory vowel nasalization with little restriction on carryover nasalization into a following vowel. The maximum peak nasal flow is delayed until the oral release of a nasal for coronal articulations, indicating a delayed velum opening gesture overall. The control of anticipatory nasalization appears similar to nasal airflow patterns for French non-nasalized vowels in oral vowel plus nasal environments (Delvaux et al., 2008) and anticipatory nasalization patterns for other languages (Clumeck, 1976). Findings from this study show that Bininj Kunwok speakers use language specific strategies to limit anticipatory nasalization, enhancing place of articulation cues at a site of intonational prominence which also has the most place of articulation contrasts within the language. The patterns of airflow suggest enhancement and coarticulatory resistance in prosodically prominent $\mathrm{VN}$ and VNC sequences which we interpret as evidence of speakers maintaining phonological contrast to enhance place of articulation cues.
\end{abstract}




\subsection{Introduction}

The typical phoneme inventory of an Australian language, has nasals matched with oral stops at up to seven places of articulation (Butcher, 2006). The phoneme inventory has a higher proportion of sonorants than obstruent consonants when compared with the majority of the world's languages (Lindblom \& Maddieson, 1988). This richness is not extended into the manner of articulation domain however, with both phonemic fricatives and affricates largely absent from the inventories of most Australian languages (see Fletcher \& Butcher, 2014 for an overview). In order to maximize place of articulation cues coarticulatory processes are highly controlled in certain prosodic positions.

The role of coarticulation in language comprehensibility and sound change is one of the prevailing and fundamental questions in phonetics today (Harrington, Kleber, \& Reubold, 2013). The path toward sound change is initiated when listeners misinterpret the synchronic coproduction of adjacent segments and re-phonologize them over time (Ohala 1993; Hajek 1997). The similarity in the phonologies across Australian languages, despite the high degree of typological diversity in terms of linguistic and social structure for both Pama-Nyungan and nonPama-Nyungan language groups, would indicate that these phonologies have been relatively stable across at a very great time depth (Evans, 1995; Koch, 2014; Harvey and Mailhammer, 2018).

The central question raised by this claim is the set of phonetic conditions that would serve to maintain this kind of long-term phonological stability? We conjecture that by limiting coarticulation at certain prosodic locations, the opportunity for speakers of Australian languages to apply phonological re-analyses that result in sound change, could also be limited. A synchronic stability may be achieved by resisting coarticulation at certain prosodic positions in the word, thus enhancing syntagmatic place of articulation cues within segment transitions. We examine the phonetic patterns found in Bininj Kunwok ${ }^{1}$ (BKw) ['pının 'konwok], an Indigenous Australian language spoken in the Western Arnhem Land region of the Northern Territory in order to test these hypotheses.

Bininj Kunwok has a phoneme inventory with consonants at five places of articulation. A striking observation, is that nasal segments in Bininj Kunwok and across Australian languages

\footnotetext{
1 The language, also known as Bininj Gun-wok, Mayali, Kunwinjku or Gunwinggu, is a dialect chain consisting of five mutually intelligible, geographically adjacent varieties: Kunwinjku, Kuninjku, Kundjeihmi, Kundedjdjnjenghmi and Kune (with 2 sub-varieties) and additionally the koine, Manyallaluk Mayali (Evans, 2003a).
} 
more generally show very little anticipatory—right-to-left — coarticulation of nasalization, and also show extensive perseverative-left-to-right or carry-over-coarticulation (Butcher, 1999). This resistance to nasal coarticulation is most tightly controlled at a prosodic position that contains the majority of contrasts in the language.

This paper presents data on nasal articulation in a single Australian language using an aerodynamic analysis of vowel and nasal sequences with the aim of establishing the extent and directionality of nasal coarticulation in Bininj Kunwok. Furthermore we explore the phonetic realization of nasals and the primacy of sonorants and voiced consonants in Indigenous Australian languages more generally.

\subsection{Background}

\section{Coarticulation and Nasalization across languages}

Many speech gestures, such as lip rounding (Benguerel \& Cowan, 1974) and nasalization (Moll \& Daniloff, 1971) show that the co-ordination of coarticulation resulting from intergestural timing is, often language specific (Beddor \& Krakow, 1999). Coarticulatory patterns cannot, however, be explained in terms of physiological mechanisms alone and there is increasing evidence that resistance to coarticulation could be a paradigmatic enhancement that forms part of the phonetic grammar (Scarborough, Zellou, Mirzayan, \& Rood, 2015, p. 290). Unchecked coarticulation often results in phonetic realizations that are harder to keep phonemically distinct (Manuel, 1990), and it is the maximization of phonemic distinctiveness in a perceptually important prosodic position that is thought to be a major motivation for the tight control of anticipatory coarticulation in Australian languages. It has been assumed that in languages such as $\mathrm{BKw}$, which do not have contrastive nasalized vowels, there would be extensive anticipatory coarticulation allowed, as there is no phonological reason to keep these phones distinct. Huffman, 1988 shows for Akan, a language with contrastive nasalization of vowels and Agwagwane, a language that does not, that patterns of anticipatory nasalization are related to the phonology of a language.

Language-specific control of coarticulatory gestures gives an insight into the planning of complex inter-gestural movements and their function within the speech system (Whalen, 1990). A central question is whether coarticulation is actively controlled to increase language comprehensibility and to ensure phonemes remain phonologically contrastive and additionally whether there are prosodic positions in which this enhancement is more likely to occur? 
The co-ordination of two independent gestures is essential for nasal articulation and these events are rarely synchronous (Flege, 1988, p.534). Nasalization, associated with a nasal phoneme, blends with surrounding sonorant segments possibly leading to the obfuscation of acoustic place of articulation cues transitions into and out of, the segment. The co-ordination of two gestures, closure in the anterior oral cavity and velum lowering, is shown to be highly language specific with the resulting articulation under the influence of both muscular and aerodynamic constraints (Proctor et al., 2013).

The phasing of gestures can result in nasalization either anticipating the oral gesture in a nasal or spreading into following segments. Anticipatory nasalization is reported as being under the conscious control of the speaker and may require significant preplanning as the velum has been described as a 'sluggish' articulator (although see below). English in particular has extensive anticipation of nasal gestures and this has been shown to be common across many languages (Bell-Berti, Krakow, \& Ross, 1993; Bladon \& Al-Bamerni, 1982; Cho, Kim, \& Kim, 2017). Rather than being slow, the muscular movement required to lower the velum may in fact be relatively rapid. Ohala (1975) argues that there is little experimental evidence to demonstrate that the velum articulates more slowly than the lips or larynx and its movement is likely to be less slow than the tongue body (Hudgins \& Stetson, 1934, cited in Ohala, 1975). In addition to active muscular control, the velum can lower rapidly in response to changes in aerodynamic state of the vocal tract, independent of closure in the oral cavity.

In contrast to anticipatory nasalization, carryover or perseverative nasal coarticulation is considered a by-product of inherent biomechanical (or mechano-inertial) properties within the velopharyngeal system (Chafcouloff \& Marchal, 1999, p.75). As introduced above, anticipatory nasalization has been shown to be under the active control of a speaker (Recasens, 1989) whereas this is not the case in carry-over situations. In a study of Standard Italian, Farnetani and Kori (1986) found aerodynamic evidence that nasality for apico-alveolar nasals was more prolonged and more visible during the following vowel rather than during the preceding vowel. Similar patterns are found in Spanish, where vowels before nasals also have velar port opening timed with the oral gesture of the nasal (Solé, 1995). Carryover coarticulation in French follows a similar pattern to that of Spanish and Standard Italian, with non-phonemically-nasalized vowels showing very little anticipatory nasalization but with the presence of extensive carryover in a post-nasal vowel environment (Delvaux, Demolin, Harmegnies, \& Soquet, 2008). An aerodynamic corpus of read speech utterances in French showed that there was also very little anticipatory nasalization in the non-nasalized vowels and that the nasal gesture was anticipated slightly sooner for high vowels when compared with low vowels (Basset, Amelot, Vaissière \& 
Roubeau, 2002).

In Austronesian languages, Riehl (2008), examined the phonetic properties of nasal obstruent sequences in Tamambo and Erromangan spoken in Vanuatu, and Pamona and Manado Malay spoken in the Indonesian archipelago. Cohn and Riehl (2008) extend this analysis to examine nasals and stops in two environments: clusters and what they term unary sequences, equivalent to pre-stopped or post-ploded nasals. Riehl (2008) argues that a clear description of the differences between these sequences is a gap in the phonological literature (c.f. Maddieson, 1988; Maddieson \& Ladefoged, 1993; Maddieson, 1989; Riehl \& Cohn, 2011). A similar complex nasal articulation is often found phonetically and sometimes phonologized in some Australian languages.

Results from American English show that speakers use extensive anticipatory vowel nasalization before nasal segments. This has been demonstrated experimentally by Clumeck (1976), Krakow (1999) and Solé (1992, 1995) amongst others. Languages such as Brazilian Portuguese show a similar pattern of anticipatory nasalization, whereas in languages such as French, Chinese, Swedish and Hindi the velum is opened far later, with less anticipation of the following nasal (Clumeck, 1976). American English listeners are also highly attuned to the presence or absence of nasalization in the speech signal and listeners "... attend to the acoustic effects of overlapping articulations in real-time processing” (Beddor, McGowan, Boland, Coetzee, \& Brasher, 2013, p.2365). This research concurs with previous studies by Fowler and Brown (2000), that “...listeners are highly accurate in identifying consonants as oral or nasal regardless of whether the preceding vowel is oral or nasal..." but "...their reaction times were faster when the vowel had appropriate nasality" (Beddor et al., 2013, p.2351). The question remains whether these coarticulatory patterns are used as a way to recognize word meanings or whether the co-articulation is biomechanical and filtered out from the signal.

\section{Nasal Coarticulation in Australian Languages}

The focus of this paper is to investigate whether, in order to control anticipatory gestures, advanced planning is needed, motivated by a need to preserve place of articulation cues. In Australian languages nasals are prevalent and can be found in both syllable onset and coda positions, with almost no restriction on place of articulation although there is neutralization of retroflexion in word initial position for many languages (O'Grady, Voegelin, \& Voegelin, 1966, pp 139-144; Dixon, 1980; Hamilton, 1996). A nasal can form part of either homorganic or heterorganic word medial clusters, with very limited regressive place assimilation (Fletcher \& Butcher, 2014). There is a strong tendency to produce sequences of non-nasal segments 
followed by nasal segments, with a delay in the opening of the velar port until after the oral closure of the nasal stop (Butcher, 1999, 2006; Butcher \& Loakes, 2008). A temporal delay in anticipatory nasalization may limit the extent of coarticulation of a nasal with the surrounding segments and thus enhance place of articulation cues for the nasal consonant. This restriction on nasal coarticulation may be essential for preserving phonemic cues at an interface between two adjacent phones that has the maximal possible number of contrasts in the language and maximizing contrastiveness.

Most phonological distinctions are found within the coronal class (Butcher, 2006; Tabain, Butcher, Breen, \& Beare, 2016). Vowel systems tend to be small with between 2 and 6 vowels with 3 or 5 the most common with no phonological nasalization ${ }^{2}$ (Butcher, 1994, Fletcher \& Butcher, 2002). Australian languages tend to only have a full range of place of articulation contrasts intervocalically and word medially, and consequently the transition from vowel to medial consonant is very perceptually important at a lexical level in order to cue meaning differences. In terms of prosodic information, accentual prominence tends to fall regularly on the first syllable or second syllable of a prosodic word. When all of this is combined with a relatively small vowel system, the importance of the nasal transitions in ensuring comprehensibility comes to the fore.

Cues to place of articulation are often marginal in nasals, with the spectral changes that signal consonant identity found mainly within the transition between vowels and nasals (Recasens, 1983). This indicates that formant transitions at the margins of the nasal convey the bulk of the place of articulation information. The low frequency murmur in nasals alone may not be sufficient to cue place of articulation (e.g. Miller \& Nicely, 1955 and Benkí, 2003 for American English, and Recasens, 1983 for Catalan), although Tabain et al. (2016, p.890) find that there are differences between bilabial and velar nasals in terms of spectral shape and frequency of the anti-resonances which may be used contrast these with coronal consonants. A delay in velum opening, however, provides the maximum opportunity for the retention of transitional cues within the speech spectrum and this may aid in the perception of consonant place of articulation (Butcher, 2006; Fletcher, Butcher, Loakes, \& Stoakes, 2010).

A subset of Australian languages with highly polysynthetic morphology such as BKw, allow for a large range of heterorganic clusters involving nasals. It is speculated that the need to preserve place of articulation in both clusters and singletons will determine the degree and extent of coarticulation (Butcher, 2006). An electropalatographic study of BKw (Kune dialect)

\footnotetext{
2 A single Australian language, Anguthimri has been documented with nasalized vowels (Crowley, 1981).
} 
involving a sequence of an $/ \mathrm{n} /$ followed by $/ \mathrm{k} /$ in the word Ankabadbirri (geographical location), shows very little place anticipation of the velar stop in the articulation of the preceding alveolar nasal (Butcher, 2006). This constraint on anticipatory coarticulation extends to languages without a polysynthetic structure such as Warlpiri (Fletcher, Loakes, \& Butcher, 2009) and Iwaidja (Fletcher, Butcher, Loakes, \& Stoakes, 2011), both which allow a certain degree of temporal coproduction but limited spatial modification of the apical nasal in apical nasal + dorsal clusters (Fletcher, Butcher, Loakes, \& Stoakes, 2010). Some examples of words in Warlpiri that illustrate a preference for anticipatory coarticulatory resistance include yinka /'jinka/ 'laughter' which is phonetically realized as ['jinke], but never *['jinke] even in connected speech (Butcher, 2006). This pattern is thought to be unusual amongst the world's languages as there is considerable cross-linguistic experimental evidence to show that synchronic assimilation is predominantly anticipatory, rather than perseverative. This anticipation of the following gesture is thought to be a result of preplanning to increase intelligibility but in Australian languages this tendency would obscure vital phonetic cues to phonemic differences meaning that alternative strategies are required.

\section{Positional Effects and Post-Tonic Consonants}

There is considerable synchronic and diachronic evidence across languages to show that syllable final consonants are more unstable than syllable initial consonants and this effect extends to higher order prosodic domains for example, domain initial strengthening and associated domain final weakening (Fougeron \& Keating, 1997; Keating, Cho, Fougeron, \& Hsu, 1998). This weakening effect can apply differently for different manners of articulation, however. Fougeron (2001) for French, observed that phrase-initially nasal airflow in /n/ was reduced when compared with the same sound phrase-medially. Cho and Jun (2000) explain this effect by noting that with weaker nasal airflow nasals become less sonorant, and “...more consonantal in domain-initial positions" (Cho and Jun 2000, p.58). This is cited as an example of a syntagmatic contrast enhancement whereby “... what is strengthened domain-initially is 'consonantality' of the segment, thus enhancing the syntagmatic contrast with the following vowel." (Cho and Jun 2000, p.58; Cho et. al, 2017). This can be used together with a paradigmatic contrast which uses more extreme phonetic cues to keep phonemes in a language distinct.

For Australian languages, observations indicate an articulatory strengthening of oral consonants after prominent vowels, rather than those in the initial position, which serve to enhance place of articulation cues. This contrast between vowel and consonant allows a syntagmatic contrast between the two adjacent segments. But the increase in prominence is 
achieved by preserving phonetic cues which allow the enhancement of a linguistic contrast in both a syntagmatic (structural) and paradigmatic (lexical and phonemic) manner (Pierrehumbert, 1990; Cho, 2001). This is assumed to aid language comprehensibility. This has been found in Warlpiri where there is lengthening of consonants after stressed vowels however pre-boundary lengthening is not prevalent in contrast to languages such as English (Pentland, 2004). This phonetic lengthening phenomenon that is found across Australian languages is termed post-tonic lengthening by Butcher (2006). The term post-tonic, refers to the consonant found immediately after the vowel hosting a major intonational prominence in Australian languages. It has been further argued that the prominent "post-tonic" consonant is part of the segmental sequence that hosts the accentual prominence gesture (Fletcher, Stoakes, Singer, \& Loakes, 2016). This post-tonic position is usually morpheme or word medial and very important for language comprehensibility as it is site of the majority of the phonetic contrasts in Australian languages (Hamilton, 1996).

\subsection{Aims and research hypotheses}

The aim of this study is to report patterns of nasalization in Bininj Kunwok and examine the coarticulation of nasals in three intervocalic positions which are in the "post-tonic" position. Measurements are taken from a singleton nasal found between two vowels (VNV) and from a nasal phone forming part of a cluster with an oral plosive (VNCV or VCNV). The aim is to test the extent and directionality of nasalization in the language in each of these environments.

The primary research question asks whether speakers of $\mathrm{BKw}$ anticipate a nasal in a $\mathrm{V}_{1} \mathrm{NV}_{2}$ sequence by lowering the velum before the onset of the oral closure of the nasal. The extent of anticipatory nasalization will be measured by labelling the first rise in airflow relative to oral closure. The degree of velum opening will be inferred by measuring any increase in nasal airflow during the first vowel $\left(\mathrm{V}_{1}\right)$ in a $\mathrm{V}_{1} \mathrm{NV}_{2}$ sequence. The directionality will be inferred using a combination of acoustics and aerodynamics. Does a delay in velum opening and an associated lack of anticipatory nasalization correlate with a delay in peak nasal flow with respect to oral closure? A further question explores whether airflow patterns differ based on the place of articulation of a nasal?

Based on earlier findings for the same language, we predict that nasals will also have a longer duration in intervocalic nasal + consonant (NC) clusters (Fletcher et al., 2010). Recall from earlier discussion that this has previously been interpreted as a strategy to block extensive anticipatory coarticulation. It remains to be seen, however, whether the non-nasal consonant in a $\mathrm{V}_{1} \mathrm{NV}_{2}$ sequence shares similar timing patterns to initial nasals in $\mathrm{VNC}$ sequences. 
A final experiment presents an investigation into the temporal patterns of nasal flow in relation to oral closure. This experiment examines the patterns of peak delay in nasal airflow as a way to ascertain the extent of carryover nasalization in the language.

\subsection{Methods and Materials}

\section{Speakers and word list}

The recordings in this study are from five female ${ }^{3}$ speakers of BKw (Kunwinjku variety) at Mamardawerre outstation, Central Arnhem Land in Australia's Northern Territory. Participants repeated a list of $\mathrm{BKw}$ words comprising disyllabic lexical items containing both word initial and medial nasals as singletons and in clusters. The phonotactic structure of BKw allows nasals to be articulated in many positions within a phonological word and consequently stop clusters are numerous, with nasals produced in both syllable initial and final position (Evans, 2003a, p. 96). Intervocalic nasals, which are not common in the lexicon were measured. Clusters in contrast, are very common and the language allows homorganic and heterorganic with nasals are in the first and second position within the cluster. This high prevalence of clusters is due to the polysynthetic nature of the language and the fact that common morphemes are usually nasal final.

The word lists were compiled by the first and third authors, consulting a comprehensive pandialectal Bininj Kunwok dictionary (Garde, in preparation) and additionally the Kunwinjku learners dictionary (Manakgu \& Etherington, 1996). The list was then checked and revised by the first author in consultation with BKw speakers at the field site to ensure both semantic and phonological accuracy. During each experiment, the participating speaker completed three repetitions of the entire word list (95 words), giving a total of 1710 tokens. A subset of this wordlist (shown in table 1) provides the 106 tokens from the five speakers included in this study.

\footnotetext{
${ }^{3}$ There are not thought to be any sex specific differences in nasal articulation although this cannot be discounted and impressionistic aerodynamic results from male speakers show very similar patterns.
} 
Table 1 The words containing intervocalic medial nasals (N), Included in this study. $V=$ vowel, $C=$ oral plosive consonant.

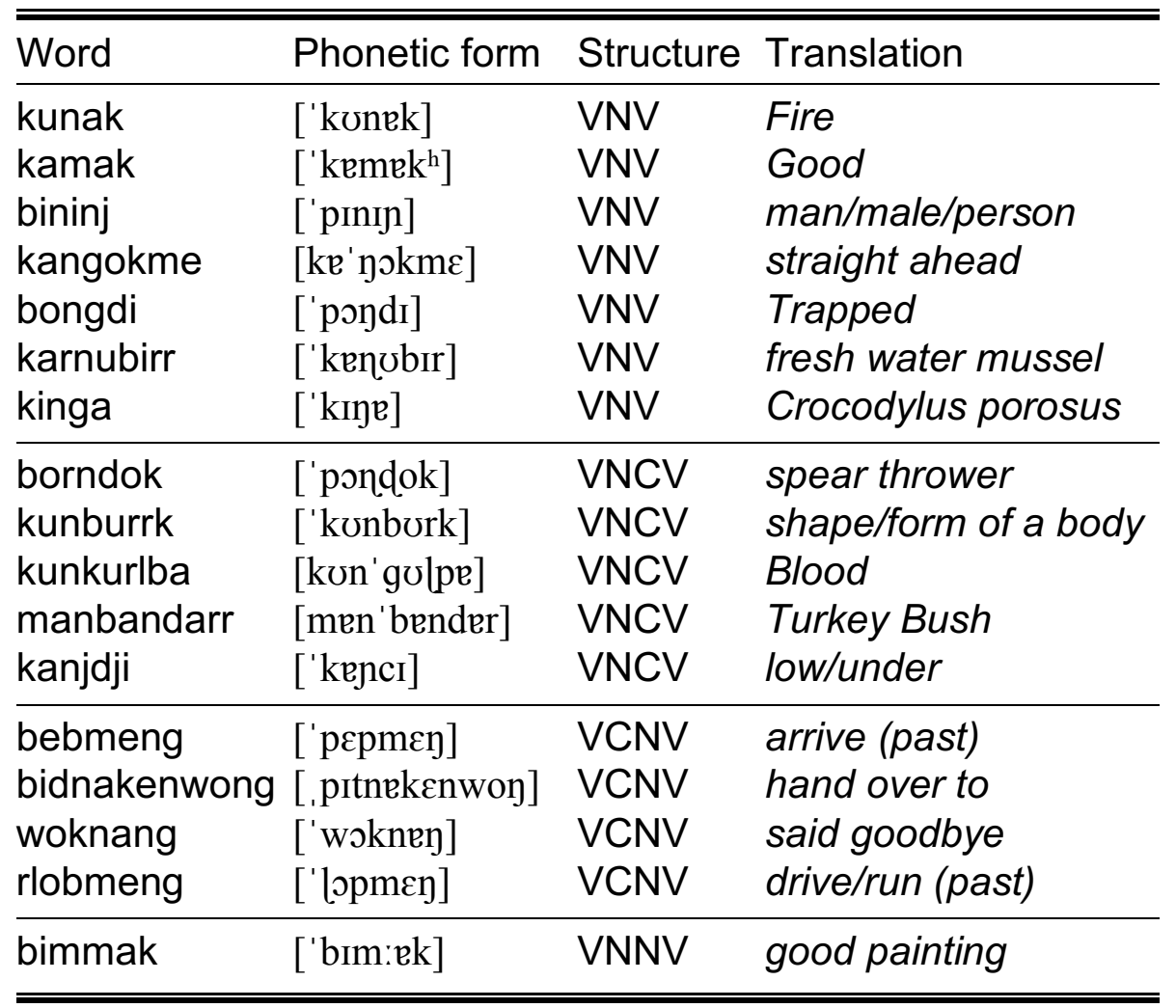

Each target word was embedded in a carrier phrase and the participant uttered the word in the following way, with the target word in bold:

(1)

$\begin{array}{lllll}\text { Yuwun } & \text { yiyime } & \text { kinga } & \text { yiyimen } & \text { kunak. } \\ \text { PROHI } & 2 / 3 . \text { say.N } & \text { 'crocodile } & 2 / 3 . \text { say.N } & \text { 'fire'. } \\ \text { jo:n } & \text { 'I:me } & \text { 'kıne } & \text { 'ji: men } & \text { 'konek }\end{array}$

'No, you don't say “crocodile", you say "fire"'.

The design of the word list controls for place of articulation and word stress as far as is possible in an elicited task. The target words were spoken in two positions within the carrier phrase: a corrective focus position which was utterance final, in a phrase location most likely to attract a major intonational prominence in the language, and also in utterance-medial position where the word was more likely to attract informational focus. For some speakers, a clear intonational break was produced after the first phrase. Prior analyses suggest that there is no major difference in degree of accentual prominence between the two utterance locations, medial and final (Fletcher et al. 2010). Only tokens that were uttered in an intonational focus position without an intonational break after the first phrase were included in the analysis, however. The final list used in this experiment comprised words containing singleton nasals and homorganic 
and heterorganic clusters of nasals and stops. When surveying the available dictionaries of the language and after extensive elicitation and consultation with Kunwinjku first language speakers, it was found that some stop and nasal sequences - and nasal and stop sequences - are entirely absent from the lexicon. Notably missing are heterorganic sequences involving apicoalveolar and apico-postalveolar (retroflex) consonants (Carroll, 1976; Etherington \& Etherington, 1998; Evans, 2003b; Garde, in press; Manakgu \& Etherington, 1996). Apicoalveolar homorganic clusters (/dn/) are commonly found within the Eastern dialects of BKw such as Kuninjku. This is due to the addition of the nominal suffix -no which is cognate to the Class-IV nominal prefix kun- in Kunwinjku used in the language to indicate non-human, nonvegetable objects. The -no morphme is very common word finally (Evans, 2003b). The proper noun Kundedjnjenghmi (the name of a Bininj Kunwok variety) contains an homorganic palatal cluster /cp/ which is an example of a sequence that is under-represented in the language (homorganic plosive plus nasal). In general, homorganic plosive plus nasal sequences are far less common than heterorganic sequences.

All target words apart from the word bininj 'male/person', contain a word initial velar oral stop $[\mathrm{k}]$ to control for any phonetic effects that may arise from segments preceding the nasal. From impressionistic surveys of these data, voiceless oral plosives reset the velum to the closed position particularly when spoken in word initial position. In this word list, it was not possible to control for vowel quality due to the small sample size and restricted number of available target words. In addition to these considerations, nasal initial words also were excluded due to the possible effects of carryover nasalization from the initial nasal. There are nasals present in the carrier phrase which may introduce long range carryover nasalization effects, but as the carrier phrase is kept constant the potential effect on the results is assumed to be minimal.

\section{Aerodynamic Recordings and Measurements}

Aerodynamic techniques are amongst the most reliable methods for indirectly inferring the movement of the velar port (Krakow \& Huffman, 1993). The speaker specific nature of aerodynamic data, however, makes cross-speaker comparisons non-trivial. Each speaker has an inherent lung volume, and the flow rate during speech is dependent on the rate and intensity of the speech act. These speaker and utterance specific parameters cannot be estimated by observation of the gender and morphology of a speaker. Despite these interspeaker differences, the flow-rates are generally highly stable for any given speaker in a controlled speech task, with multiple repetitions showing very similar peak values (Baken \& Orlikoff, 2000, p.355). A general observation of flow rates across speakers is that nasal airflow is a considerably lower 
volume when compared with oral airflow due to the smaller aperture of the nasal cavity and velar port. Ladefoged (2003) reports that nasal flow comprises on average 13\% of the total airflow in the speech system. The reduced airflow in nasals means that there can be a low signal to noise ratio which can be highly affected by glottal pulsing during voicing. The combination of these factors can make interpretation of nasal signals relatively challenging.

The method used in this study during the data gathering phase follows that of Yanagihara and Hyde (1966) in their study of bilabial stops. Multichannel articulatory recordings were gathered via a Scicon R\&D airflow mask (OM-2) containing an inbuilt microphone and nasal mask (NM-2) connected via catheters to an EIPF-4 transducer base. This was then interfaced with a Scicon R\&D 916 capture device (Scicon R\&D, Inc. California, USA). These were attached to a Dell Latitude D510 laptop running Microsoft Windows XP Professional (Service Pack 2). The airflow acquisition hardware was controlled using PCQuirer software (Version 7 , Scicon R\&D California, USA). Oral and nasal airflow was recorded via separate masks with the speaker holding a mask over their mouth and a separate mask attached to the nose by means of a strap around the head. This experimental design eliminates the risk of leakage between chambers that is possible with a partitioned mask. A microphone mounted within the oral mask enables the capture of the audio signal directly from the oral cavity.

Prior to fieldwork, the aerometric system was calibrated for oral flow oral flow $\left(U_{o}\right)$, nasal flow $\left(\mathrm{U}_{\mathrm{n}}\right)$ and oral pressure $\left(\mathrm{P}_{\mathrm{o}}\right)$ following the method described in Ladefoged (2003). Calibration was performed before commencement of fieldwork and then re-calibrated upon return to the Phonetics Laboratory at The University of Melbourne. Airflow transducer calibration was completed by placing the masks onto the Perspex cylinder of the Scicon calibration device (Scicon R\&D CAL220). Initial calibration was performed at sea level with an air temperature of approximately $20^{\circ} \mathrm{C}$. During transducer calibration, the air passes from the calibration device into the mask at 8 set rates $(0,5,10,15,20,25,30$ and 35 1/min) recorded with an arbitrary gain on the capture equipment of 5 units (millivolts). As the transducer response is not linear it must be calibrated using the polynomial equation $-(2.10-8) \mathrm{x}^{2}+0.0011 \mathrm{x}+0.3846$, where $\mathrm{x}$ is measured in millivolts $(\mathrm{mV})$. The millivolt values were then converted into $1 /$ min using the output of the calibration device as reference.

Air temperature at the field site fluctuated between $29^{\circ} \mathrm{C}-43^{\circ} \mathrm{C}$ during recording sessions and all measurements were taken $27 \mathrm{~m}$ above sea level. For the nasal channel, the zero level was very variable, however and consequently in the majority recordings the signal has been offset from the zero baseline. This offset is recalibrated to zero by measuring a steady-state 
portion of the signal away from obvious respiration (see Figure 1. above). This zero-correction is considered during the analysis and the variability was explainable and did not cause us to question the resulting signals (see below for method). The volume velocity of flow in both the oral and nasal channels is measured in litres per minute $(1 / \mathrm{min})$ and then converted to millilitres per second $\left(\mathrm{ml} / \mathrm{s}\right.$ or the equivalent SI unit, $\left.\mathrm{cm}^{3} \mathrm{~s}^{-1}\right)$.

All acoustic data were recorded either directly from the aerodynamic mask as mentioned above using the inbuilt microphone in the Scicon R\&D airflow mask (OM-2) or high-quality audio recordings with a Sony ECM-MS957 Electret Condenser microphone and recorded onto a Marantz PMD690 Portable Flash Recorder, as mono, uncompressed Broadcast WAV files at a $48 \mathrm{kHz}$ sample rate and a bit depth of 16 bits. The aerodynamic acoustic data were recorded with at a significantly lower $11 \mathrm{kHz}$ sample rate with a bit depth of 16 bits. The lower quality in these recordings precluded its use in a spectral or formant analysis. Additionally, the aerodynamic audio channel had marked attenuation of the higher frequencies $(>1000 \mathrm{~Hz})$ due to the design of the oral mask and the lack of nasal information in the signal. The information in the higher frequencies was sufficient as a guide for the subsequent segmentation and labelling of the sound files and synchronous airflow signals but unfortunately not for further acoustic analysis (see Stoakes, 2013 p.143 for further details on channel processing and filtering).

\section{Database, Measurements and analysis}

The database of sound files, time-aligned physiological signals and hierarchical label files were managed within The Emu Speech Database (emuR, Version 0.2.3) (Winkelmann, Jaensch, Cassidy, \& Harrington, 2017). All recordings were initially segmented and labelled with Praat (versions 5.0.0-5.4.02 (Boersma \& Weenink, 2015)) and the Text Grid label files were converted into the latest Emu Database format using a function that is part of the emuR package (emuR::convert_TextGridCollection()) (Winkelmann et al., 2017). All data were analyzed within the R environment (R Core Team, 2017). The statistical analyses were computed using the lme4 (Bates, Maechler, \& Bolker, 2011), gss (Gu, 2014) and fda (Ramsay et al., 2017) R packages. Visualization and plotting of the aerodynamics were output using the ggplot 2 package (Wickham, 2009).

\section{Acoustic Duration Measurements}

The duration measurements are based on the acoustic signal and this experiment examines both single nasals and nasals that form part of a cluster. The physiological experiment uses aerodynamic recordings and is divided into three sub-experiments, all of which test the extent 
and directionality of nasalization in BKw.

Nasalization is a gradient phenomenon and as nasals are relatively sonorous, with acoustic energy found throughout the speech spectrum it is difficult to place discrete boundaries at the transitions between vowel and nasal. It is particularly difficult if nasalization begins before the onset of oral closure. As with all phonetic labelling, strict measurement criteria must be employed to ensure replicatable results. With these considerations in mind, initial segmentation was based on the acoustic waveform and associated spectrographic information rather than with explicit reference to the aerodynamic channel. The duration of a nasal was measured at the offset of the vowel at the cessation of regular high frequency spectral activity $(>2000 \mathrm{~Hz}$ ) read from the spectrogram, which was assumed to be the moment that oral articulators form closure (see Figure 1. below). The closure phase is taken to be the time in which the oral tract was fully occluded with the articulators held in place. In this phase, there is acoustic evidence of strong anti-formant activity giving rise to spectral zeros (Harrington, 1994, 2012). The offset of the nasal is measured from the onset of high frequency spectral energy in the following vowel. Duration was measured for all vowels, nasals that were word medial, and stops that formed part of an intervocalic cluster. Acoustic measures of nasalization such as A1-P0 and A1-P1 (see Chen, 1997 and Scarborough et. al, 2015) are not included in the current study mainly due to the degraded acoustic signal. Aerodynamics is the preferred method as it gives direct information on nasalization, although it is much more challenging to gather articulatory recordings under field conditions when compared with acoustic recordings.
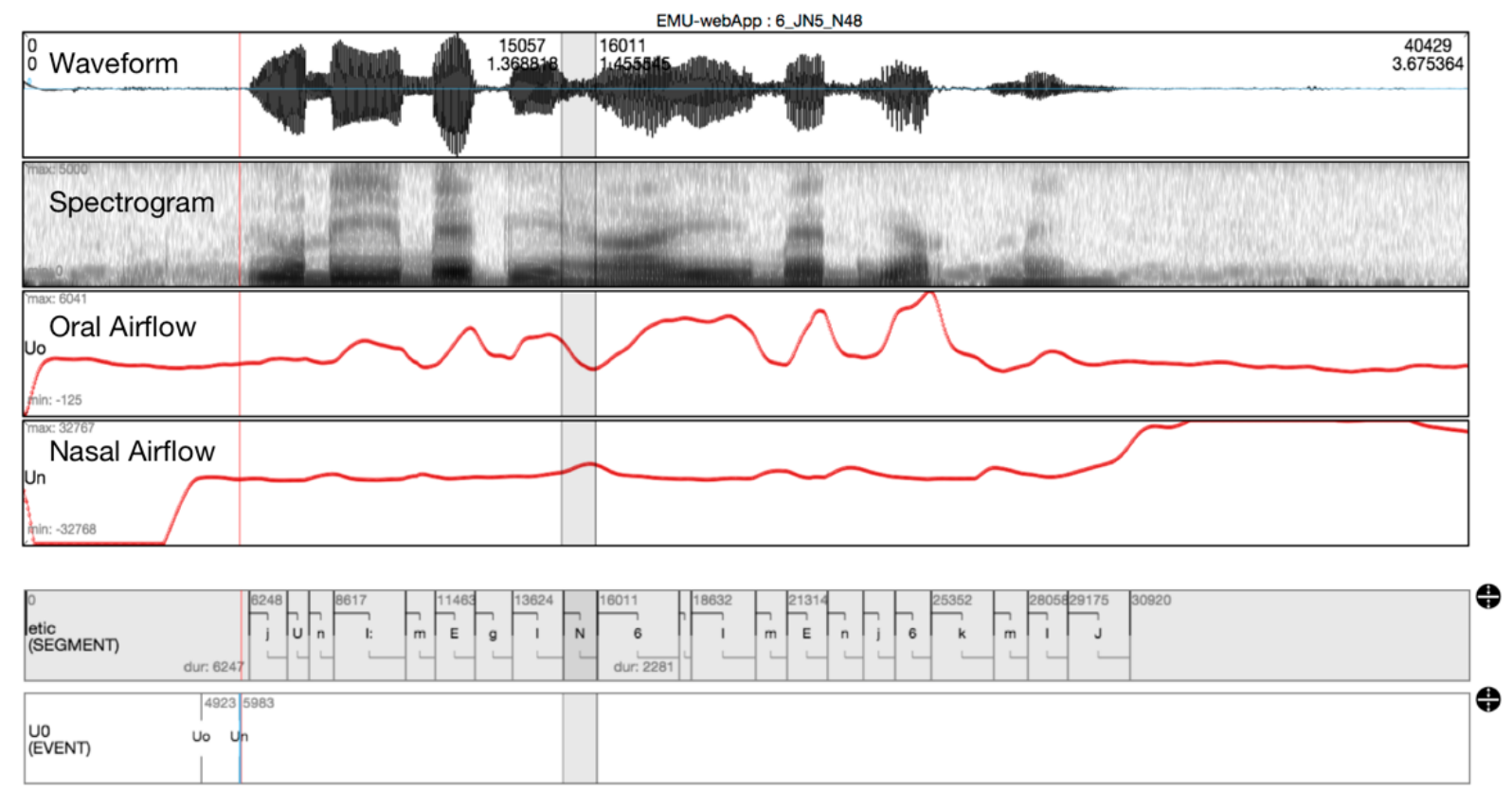

Figure 1. Labelling criteria - in the word kinga ['gije] 'estuarine crocodile (Crocodylus porosus)' with 4 signals shown in the Emu Labeller: The acoustic waveform, the spectrogram, the oral airflow and the nasal airflow. The zero-rectification for both channels is also indicated on an Event level (Uo and Un). The oral closure in the nasal is marked based on labelling landmarks in the acoustic waveform. 
The following duration and aerodynamic measurements were extracted from the corpus and associated Emu Speech Database. The durational results derive from a larger sample of words than the aerodynamic results from the same five speakers, and only experimental tokens were measured with all nasals found within carrier phrases excluded:

1. The duration of singleton nasals in a VNV sequence. (see Table 2)

2. Mean oral and nasal flow in VNV sequences separated by place of articulation (see Tables 3. and 4.)

3. The interaction between the timing of the onset of nasalization and the timing of oral closure in nasals (see Figure 2. below)

4. Level of peak nasal airflow $\left(U_{n}\right)$ in VNV sequences using the SSANOVA technique (see Figures 5. and 6. below).

5. Registered $b$-splines for time normalized $U_{n}$ curves in VNV sequences, registered by Oral onset (Figure 7a.) and proportional nasal airflow maximum (Figure 7b.).

The duration and peak nasal airflow of the nasals as part of a VCNV and VNCV sequence (Figures 9., 10., 11., and 12.).

\section{Aerodynamic Timing Measurements}

It is possible to quantify the magnitude of anticipatory and carry-over nasalization present using the nasal flow channel $\left(U_{n}\right)$ by measuring the time at the onset of nasal airflow in relation to the point of closure using information from the nasal flow channel $\left(U_{n}\right)$ (c.f. Basset et al., 2002). In Figure 2. the value a represents the duration of anticipatory nasal airflow. The interval $\mathbf{a}$ is measured as the time between the onset of nasal airflow represented in the nasal flow channel $\left(U_{n}\right)$ and the onset of the nasal consonant, determined from the acoustic signal when there is significant dampening of formant activity and no high frequency energy. The onset is the zero point, marked in the figure using a dotted line. The interval a will return a negative value if the nasal airflow anticipates the oral closure. A delay in the onset of nasal airflow is measured as the interval ' $\mathbf{d}$ ' which will be a positive value if nasal airflow only starts to increase after the oral closure. The nasal segment is marked ' $\mathbf{N}$ ', and the preceding segment, usually a vowel, is marked ' $\mathbf{N}-\mathbf{1}$ '; the following segment, also usually a vowel, is marked ' $\mathbf{N}+\mathbf{1}$ '. The interval marked ' $c$ ' is the time of carryover nasalization from the offset of the oral closure in the nasal until either a minimum in the nasal flow channel or the end of the vowel $\left(\mathrm{V}_{2}\right)$ which ever come first. 


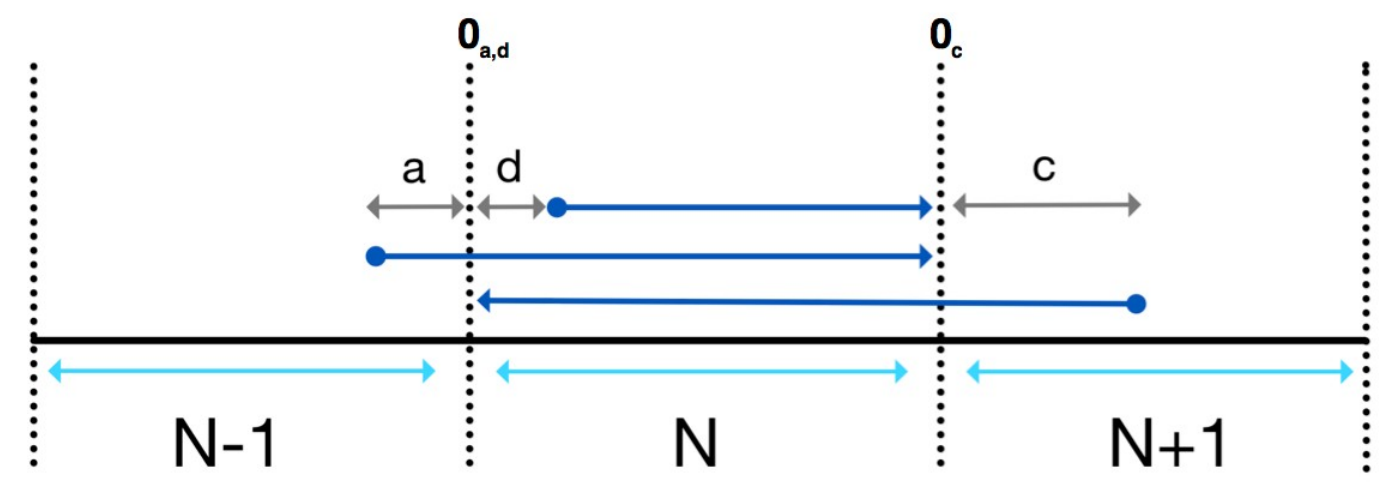

Figure 2: Measurements for the anticipation (a), delay (d) and carryover (c) of nasal airflow with respect to the acoustic labelling of oral closure $\left(0_{a, d}\right)$ and oral release $\left(0_{c}\right)$ (after Basset et al. (2002)), The dark blue line indicates the extent of nasal "a"

\section{Statistical Measures}

\section{Smoothing Spline ANOVA}

When comparing multiple aerodynamic recordings across multiple speakers it is necessary to average the signals not only for peak nasal airflow but also for time due to differences in speech rate and amplitude. In this experiment, the averaging of the peak airflow was calculated using a spline smoothing algorithm. For further information on the technique, see Davidson (2006) for an overview of the applications of spline smoothing algorithms for dynamic speech data. This method is based on the Smoothing Spline ANOVA (SSANOVA), introduced by Gu (1990) as a way of averaging complex time-series data. Each speech segment must be temporally normalized prior to an SSANOVA being calculated and then the smoothing spline function can be successfully applied. There have been several previous studies applying this technique to a variety of dynamic speech data, the most prevalent being the analysis of ultrasound tongue splines (Billington, 2014; Davidson, 2006; Heyne \& Derrick, 2015; Mielke, 2015), as well as acoustic data which have enabled the contours of dynamic formant trajectories (Docherty, Gonzalez, \& Mitchell, 2015; Haddican, Foulkes, Hughes, \& Richards, 2013; Kirkham, 2017; Nycz \& De Decker, 2006) and F0 (Yiu, 2015) across speakers, enabling a direct comparison. Related to nasalization, Carignan (2017) uses a smoothing spline averaging method to calculate statistics for nasalance and contact quotient over proportional time. For additional information about applying the spline smoothing technique to aerodynamic data, see Stoakes (2016).

The nasal airflow for each phoneme $\left(\mathrm{V}_{1} \mathrm{NV}_{2}\right)$ was measured independently and then averaged over 100 time points. As previously discussed, in order to obtain a consistent baseline value for the subsequent averaging of the peak nasal airflow, the zero level for each phoneme sequence 
containing a nasal was set using a hand labelled point in a steady-state portion of the signal away from obvious respiration (see the U0 event tier in Figure 1.). The peak nasal airflow rate for the other phonemes was then calculated relative to this steady-state airflow level (see vertical line marked in Figure 1.).

The ssanova function, which forms part of the R library gss (Gu, 2014), was applied using a 95\% Bayesian confidence interval (shown as a ribbon on the plots below). The resulting plot shows the nasal airflow rate over time for each of the nasal phonemes. This is separated by place of articulation.

As we are most concerned with the temporal domain rather than with cross-speaker comparisons in the magnitude of nasal flow, a further spline smoothing was applied to ensure that each place of articulation was temporally registered both relative to the onset of the oral closure and then also relative to the absolute maximum of nasal flow. These were calculated separately for each place of articulation. A "Functional Data Analysis" approach for approximating a curve using discrete points was computed as b-splines (or basis-splines) using the $f d a$ package within $\mathrm{R}$ (Ramsay et al., 2017). B-splines are used because they are very computationally efficient and the resulting curve is a good representation of averaged data. As with an SSANOVA, these data are first linear time normalized resulting in a proportional time over 100 points across the entire VNV sequence. In addition, within this analysis, flow values are calculated as proportional flow using the minimum flow value for each sequence as zero and the maximum flow value in the sequence as 1 which is expressed as $\Delta \mathrm{Un}$. The use of proportional flow enables airflow for different speakers to be compared directly giving information about the timing of the peak flow relative to the onset of oral closure in the nasal ${ }^{4}$. There is the potential of a great deal of variation in the slope of the airflow contours but our observations suggested that these were relatively consistent if separated by place of articulation of the nasal.

\section{General Linear Mixed Effects Models}

For static measures, general linear mixed effects models (GLMM) were used to compare durational measurements and used to correlate the aerodynamic and acoustic measurements. This procedure was only applied to static measures rather than dynamic measures such as airflow over time. The lme 4 package (Bates et al., 2011) as well as the base R environment was used (R Development Core Team, 2016). After each linear mixed effect model was constructed, a check of the validity of the model was examined using a likelihood ratio test comparing the

\footnotetext{
${ }^{4}$ The motivation for using this measure is to ensure that the averaging of the results sufficiently reflects individual flow patterns.
} 
null model to the alternative model. To test this fully, two analyses of variance (ANOVA) were computed: one with a model that includes the fixed effects (the alternative model) which was then compared with the null model that includes only the random intercepts. The model with the least degrees of freedom was selected. Throughout this study, measurements of statistical significance are reported as Chi squared $\left(\chi^{2}\right)$ with subsequent p-values calculated using the Sattherwaite approximation and Bonferroni Correction (as per the method in Harrington and Schiel, 2017) These $p$-values are considered significant at the $\alpha=0.01$ level. The language- asa-fixed-effect fallacy — as noted by Clark (1973) — was avoided by including both Speakers and Tokens (Items or Words) as random intercepts (see Baayen, Davidson, and Bates (2008) for a discussion).

\subsection{Results}

As described in the methodology section above, the second experiment follows a similar procedure to that of Basset and colleagues when measuring patterns of nasalization in French (Basset et al., 2002). The results of this study are presented in several parts. The first section reports the duration and aerodynamic results for nasals found in various positions and then looks at the timing of airflow rises in relation to the oral closure. The next section examines VNV sequences within the first disyllable in a word presenting SSANOVA results. Following on from this coarticulatory nasalization is measured using a Functional Data Analysis by looking at anticipatory nasalization for each place of articulation using a registered proportional signal. This is done in order to initially normalize for inter-speaker variation and to check that the observations we found in individual airflow curves was representative when averaged across speakers.

\section{Durational and aerodynamic measurements}

Table 2 shows the mean duration, standard deviation, and number of word medial intervocalic medial nasals broken down by place of articulation. 
Table 2: Nasal oral closure duration in $\mathrm{V}_{1} \mathrm{NV}_{2}$ sequences.

\begin{tabular}{lccccc}
\hline & \multicolumn{2}{c}{ Peripheral } & \multicolumn{2}{c}{ Coronal } & Laminal \\
\cline { 2 - 6 } & & & \multicolumn{2}{c}{ apical } & laminal \\
\cline { 3 - 6 } & bilabial & velar & alveolar & retroflex & palatal \\
\hline phoneme & $\mathrm{m}$ & $\eta$ & $\mathrm{n}$ & $\eta$ & $\mathrm{n}$ \\
\hline$\overline{\mathrm{x}}$ & 112 & 84 & 95 & 50 & 91 \\
s.d. & 60 & 28 & 54 & 9 & 36 \\
$n$ & 82 & 70 & 66 & 10 & 24 \\
\hline
\end{tabular}

The alveolar and bilabial nasals have the longest oral closure duration with mean durations of $95 \mathrm{~ms}$ and $112 \mathrm{~ms}$ respectively. The post alveolar (retroflex) nasal has a duration of between $45 \mathrm{~ms}$ and $55 \mathrm{~ms}$. The bilabial and velar (peripheral) nasals are often found in BKw high frequency words and the retroflex nasal is a rarer phoneme as it does not occur, or is neutralized along with retroflex stops, in word initial position. An LMM was calculated and when a main effect of an interaction of duration by place of articulation was tested, using speaker and item as random intercepts, all places of articulation except palatal and velar had durations that were significantly different to one other ( $\mathrm{p}>.001)$.

Table 3: Mean nasal airflow $\left(U_{n}\right)$ of segments in VNV sequences (measured in $\mathrm{cm}^{3} \mathrm{~s}^{-1}$ ).

\begin{tabular}{|c|c|c|c|c|c|c|c|c|c|c|c|c|c|c|c|}
\hline \multirow[b]{4}{*}{ VNV } & \multicolumn{6}{|c|}{ Peripheral } & \multicolumn{6}{|c|}{ Coronal } & \multicolumn{3}{|c|}{ Laminal } \\
\hline & & & & & & & & & & & & & & lami & \\
\hline & \multicolumn{3}{|c|}{ bilabial } & \multicolumn{3}{|c|}{ velar } & \multicolumn{3}{|c|}{ alveolar } & \multicolumn{3}{|c|}{ retroflex } & \multicolumn{3}{|c|}{ palatal } \\
\hline & $V_{1}$ & $\mathrm{~m}$ & $V_{2}$ & V1 & $\eta$ & $\mathrm{V}_{2}$ & $\mathrm{~V}_{1}$ & $n$ & $V_{2}$ & $V_{1}$ & $\eta$ & $\mathrm{V}_{2}$ & $V_{1}$ & $\mathrm{n}$ & $\mathrm{V}_{2}$ \\
\hline $\bar{u}_{n}$ & 3 & 39 & 31 & 7 & 52 & 18 & 5 & 35 & 26 & 3 & 27 & 24 & 4 & 33 & 28 \\
\hline s.d. & 3 & 25 & 22 & 6 & 37 & 13 & 4 & 22 & 15 & 4 & 21 & 22 & 3 & 28 & 23 \\
\hline$n$ & \multicolumn{3}{|c|}{22} & \multicolumn{3}{|c|}{17} & \multicolumn{3}{|c|}{13} & \multicolumn{3}{|c|}{10} & \multicolumn{3}{|c|}{9} \\
\hline
\end{tabular}

Tables 4. and 5. present the mean, standard deviation (s.d.) and number of tokens $(n)$ for nasal airflow $\left(\mathrm{U}_{\mathrm{n}}\right)$ and oral airflow $\left(\mathrm{U}_{\mathrm{o}}\right)$. The tables are arranged according to nasal place of articulation with the peripheral, coronal and laminal consonants grouped separately. As can be seen in Table 3, the aerodynamic results show very little observable mean nasal airflow during the initial vowel $\left(\mathrm{V}_{1}\right)$ compared to $\left(\mathrm{V}_{2}\right)$. After zero-rectification (see method above), the flow rates for $\mathrm{V}_{1}$ before all nasals except the velar $(/ \mathrm{y} /)$ are within the error threshold set at $\pm 5 \mathrm{~cm}^{3}$ $\mathrm{s}^{-1}$. This indicates that the average nasal flow over the whole sequence is very low. The oral flow results (shown in Table 4 show the flow rate is lower during $V_{2}$ when compared to $V_{1}$ in the same $\mathrm{V}_{1} \mathrm{NV}_{2}$ sequences, reflecting the higher nasal flow shown in the same context. 
Table 4: Mean oral airflow $\left(U_{o}\right)$ of segments in VNV sequences (measured in $\mathrm{cm}^{3} \mathrm{~s}^{-1}$ ).

\begin{tabular}{|c|c|c|c|c|c|c|c|c|c|c|c|c|c|c|c|}
\hline \multirow[b]{4}{*}{ VNV } & \multicolumn{6}{|c|}{ Peripheral } & \multicolumn{6}{|c|}{ Coronal } & \multicolumn{3}{|c|}{ Laminal } \\
\hline & & & & & & & & & & & & & & $\min$ & \\
\hline & \multicolumn{3}{|c|}{ bilabial } & \multicolumn{3}{|c|}{ velar } & & eoola & & \multicolumn{3}{|c|}{ retroflex } & \multicolumn{3}{|c|}{ palatal } \\
\hline & $V_{1}$ & $m$ & $V_{2}$ & $\mathrm{~V}_{1}$ & $\eta$ & $\mathrm{V}_{2}$ & $\mathrm{~V}_{1}$ & $n$ & $V_{2}$ & $\mathrm{~V}_{1}$ & $\eta$ & $\mathrm{V}_{2}$ & $\mathrm{~V}_{1}$ & $n$ & $\mathrm{~V}_{2}$ \\
\hline $\bar{u}_{0}$ & 149 & 66 & 125 & 178 & 43 & 116 & 139 & 61 & 79 & 103 & 98 & 98 & 181 & 92 & 100 \\
\hline s.d & 56 & 37 & 62 & 95 & 26 & 70 & 78 & 23 & 37 & 81 & 102 & 85 & 91 & 60 & 67 \\
\hline$n$ & \multicolumn{3}{|c|}{22} & \multicolumn{3}{|c|}{17} & \multicolumn{3}{|c|}{13} & \multicolumn{3}{|c|}{10} & \multicolumn{3}{|c|}{9} \\
\hline
\end{tabular}

It is clear from these flow results that although there are very low levels of anticipatory nasal flow there are greater levels of carry-over nasalization in vowels following nasals. These average values make it difficult to generalize patterns and show the precise timing of the velum opening gesture, however.

\section{Nasalization onset and the relationship with oral closure}

The timing of onset of nasal gesture shows considerable variability in the inter-articulator timing between articulator closure and velum lowering. The hypothesis is that nasalization, observed by an increase in nasal airflow occurs in advance of oral closure. This experiment examines the timing differences looking at whether the oral closure is before the nasal gesture or whether it is after. Figure 8 shows the duration of anticipation and delay in milliseconds from all measured speakers (see Figure 2 for a schematic diagram). The three sequences measured include a singleton nasal between two vowels (VNV), a cluster of a nasal followed by a stop also between two vowels (VNCV) and a cluster of a stop followed by a nasal between two vowels (VCNV). In the case of the clusters it has been assumed that there is a morpheme boundary between the nasal and the stop in each case based on Evans' (2003a) grammatical analysis. A morpheme boundary cannot be posited for intervocalic singleton nasals as these are not morphologically transparent in the language. Of the total number of tokens, $73 \%$ that have anticipatory nasal airflow and $27 \%$ that have a delay in the nasal airflow. As shown in the aerodynamics, the duration of both anticipation and delay very short and the onset of nasal air flow is virtually synchronous with the oral closure and well below a "just noticeable difference" set at approximately $30 \mathrm{~ms}$ (Pastore \& Farrington, 1996; Pisoni, 1977). Apparently, the velum is lowered very quickly in these examples which does not accord with descriptions of the velum as a sluggish articulator (Ohala, 1975) (Stevens, 1998, p. 43). 


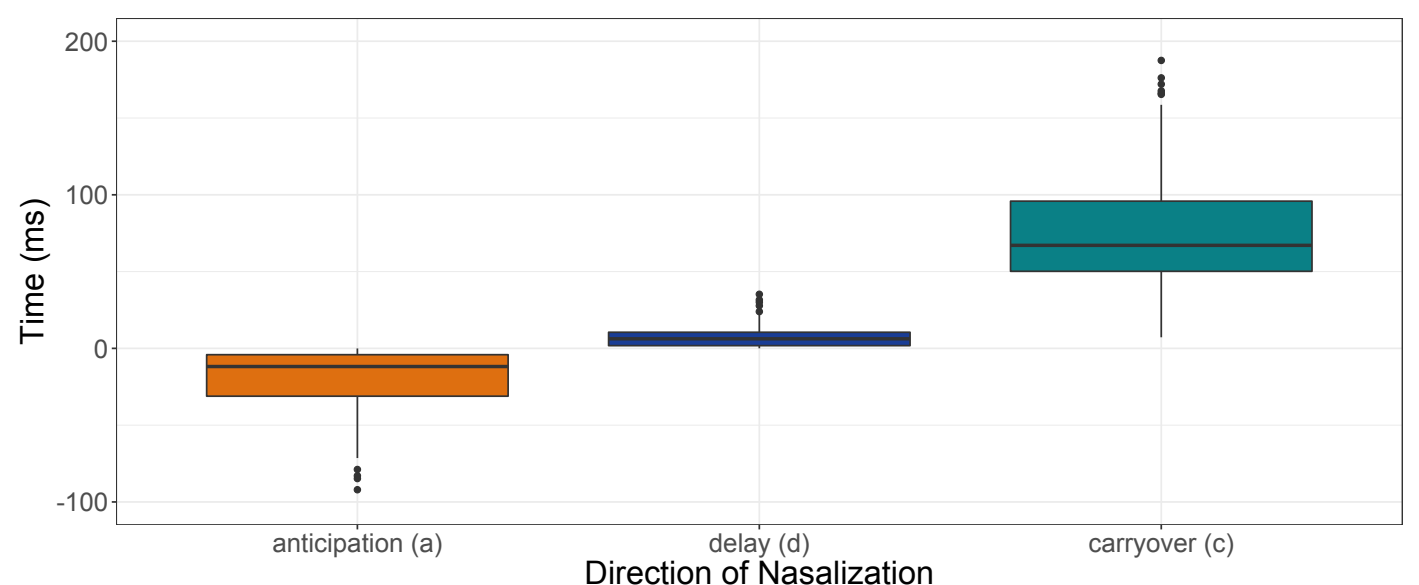

Figure 3. Magnitude of anticipation (a), delay (d), and carryover (c), in VNV sequences.

A linear mixed effect model $\left(\chi^{2}(6,435)=227, \mathrm{p}<.001\right)$ shows that a main effect of directionality of nasalization (anticipation, delay or carry-over) has a statistically significant duration effect (with speaker and token included as random intercepts). A post hoc Bonferroni test shows that the mean of the Anticipation (a) differs from the mean of the Delay (d) by $28 \pm$ $8 \mathrm{~ms}(\mathrm{p}=.004)$. Carryover (c) is $109 \pm 6 \mathrm{~ms}$ greater than Anticipation (a) (p >.001) and carryover is $81 \pm 8 \mathrm{~ms}(\mathrm{p}>.001)$ greater in duration than Delay $(\mathrm{d})$. The mean anticipation and delay are short enough to be considered co-incident whereas the carryover shows significant nasalization in the following vowel. Figure 4 shows that this pattern is largely consistent across all speakers with some speakers having greater variability of the co-ordination of the oral closure to the velar port opening gesture (BN in particular and some showing tight co-ordination of the two gestures).
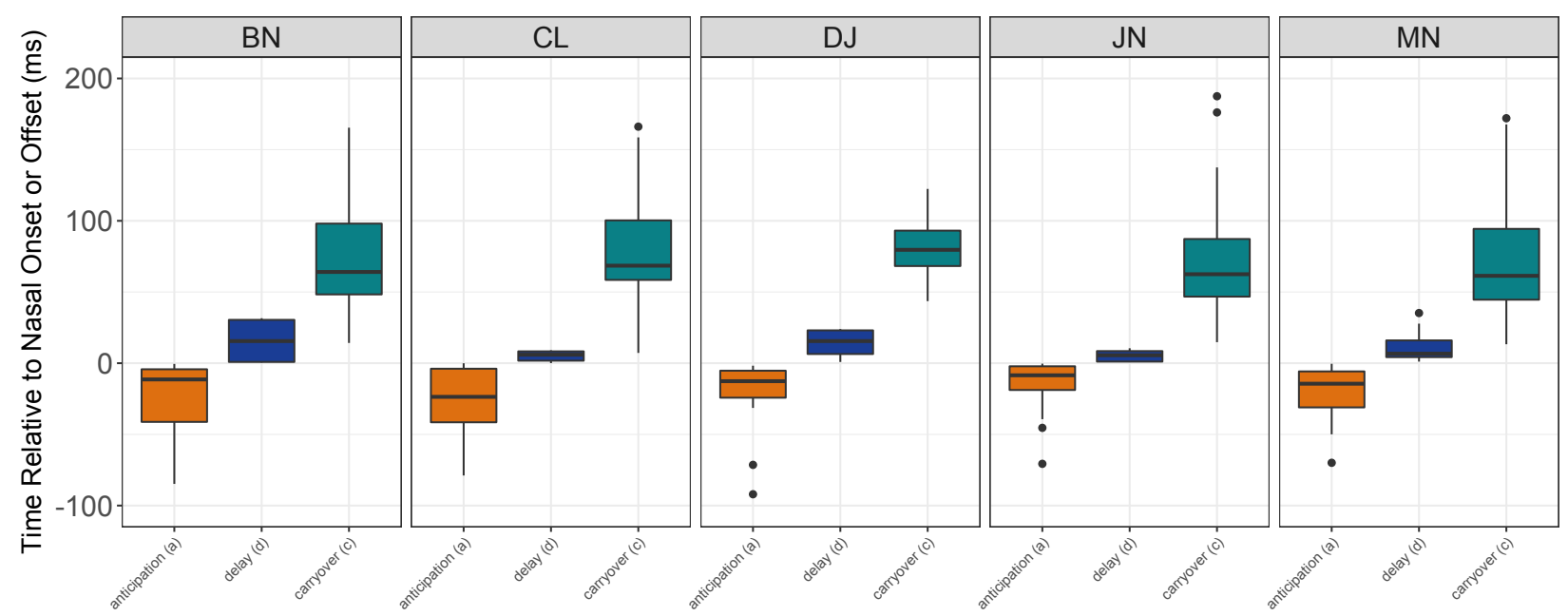

\section{Direction of Nasalization}

Figure 4. Magnitude of anticipation,(a), delay (d), and carryover (c), in VNV sequences separated by speaker.

To show the precise timing of the onset of nasal flow we can calculate this as a function of time and the plot the resulting signal. In the next section, dynamic plots of peak nasal flow are calculated using a SSANOVA analysis, and the results are presented in the following sections. 
Figure 5. summarizes the calculations for average nasal airflow $\left(\mathrm{U}_{\mathrm{n}}\right)$, measured for single intervocalic nasals. Adjusted airflow $\left(\mathrm{cm}^{3} \mathrm{~s}^{-1}\right)$ averaged over five speakers is plotted against normalized time (shown on the x-axis). The boundaries between the normalized segments are based on the hand-labelled division of vowel $\left(\mathrm{V}_{1}\right)$ and nasal $\left(\mathrm{N}_{1}\right)$, relying on the acoustic signal and spectrogram as reference. The nasal onset is assigned at the point of full oral closure and when the overall sonorance is reduced, damping the high frequency spectral information (see Figure 1 above). The time normalizing procedure is achieved by first using temporal-averaging across the entire segment ( $\mathrm{n}=100)$. A spline smoothing ANOVA (SSANOVA) is then calculated for each time normalized data vector resulting in an averaged plot for each nasal phoneme.
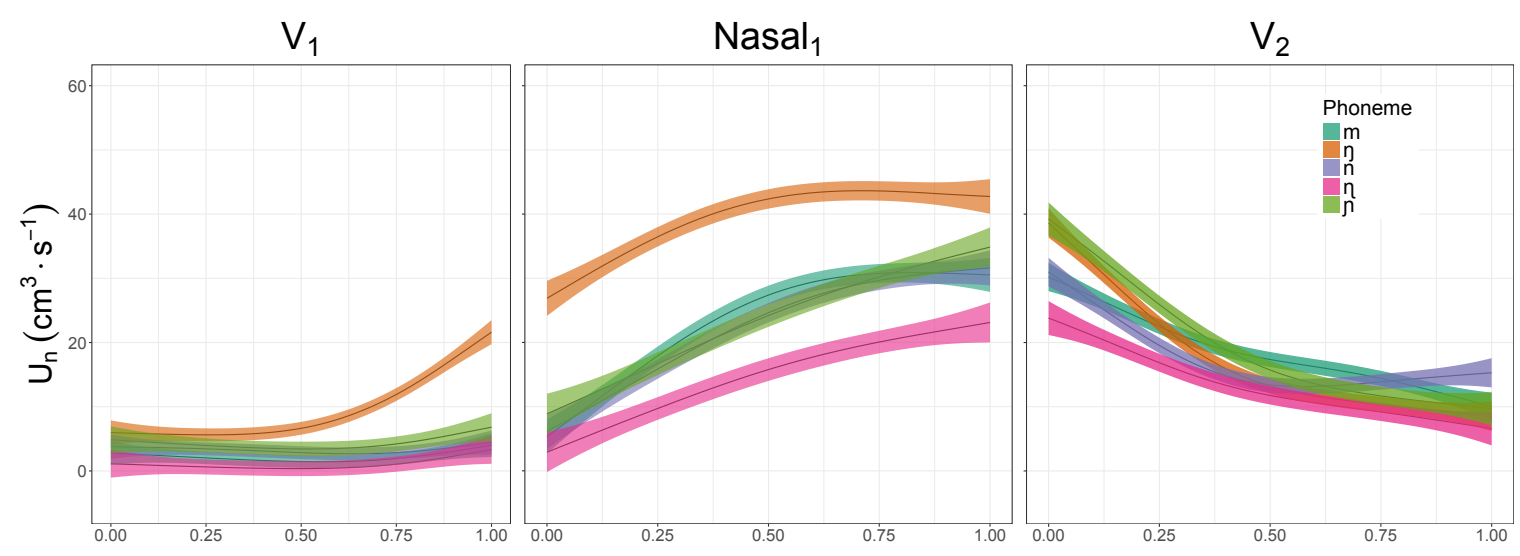

Normalized Time

Figure 5 An SSANOVA of nasal airflow(Un) calculated separately for a Vowel $\left(V_{1}\right)$, Nasal, Vowel $\left(V_{2}\right)$ sequence plotted by place of articulation.

In Figure 5 the airflow rises for the majority of places of articulation occur during the final $25 \%$ of the initial vowel. The velar nasal has greater anticipation in the vowel of the following nasal segment. In the vowel following the nasal $\left(\mathrm{V}_{2}\right)$ there is positive nasal flow throughout the entire segment for tokens regardless of place of articulation. For all nasals, the average peak nasal flow rate occurs after $50 \%$ of the oral closure, well within the nasal segment (central panel of Figure 5). This plot is consistent with the averaged flow values reported above in Table 3. These results suggest that the velar place of articulation is patterning differently to the other nasals with respect to velar port opening.

\section{Group and Interaction Effects}

The plot in Figure 5 shows the flow with respect to proportional time. In order to show statistical significance in an SSANOVA plot, a group interaction is calculated that shows each of the nasal phonemes individually. This plots the mean difference in peak nasal airflow $\left(U_{n}\right)$ between each of the phonemes when compared with the group mean over time. The values of the initial vowel $\left(\mathrm{V}_{1}\right)$, nasal and following vowel $\left(\mathrm{V}_{2}\right)$ are shown, separated by the label of the 
medial nasal phoneme. Any ribbons that intersect with the 0 line indicate that the phoneme is statistically significantly different from the group for that nasal phoneme at that particular time point. The velar place of articulation has a mean nasal airflow across the entire segment that is considerably higher than the group mean, whereas the remaining phonemes all have values showing that they very close to the group mean. The calculated mean difference across the nasal is small at approximately $2.5-10 \mathrm{~cm}^{3} \mathrm{~s}^{-1}$ although as can be seen in Figure 6 that the main difference is restricted to the end of the vowel.
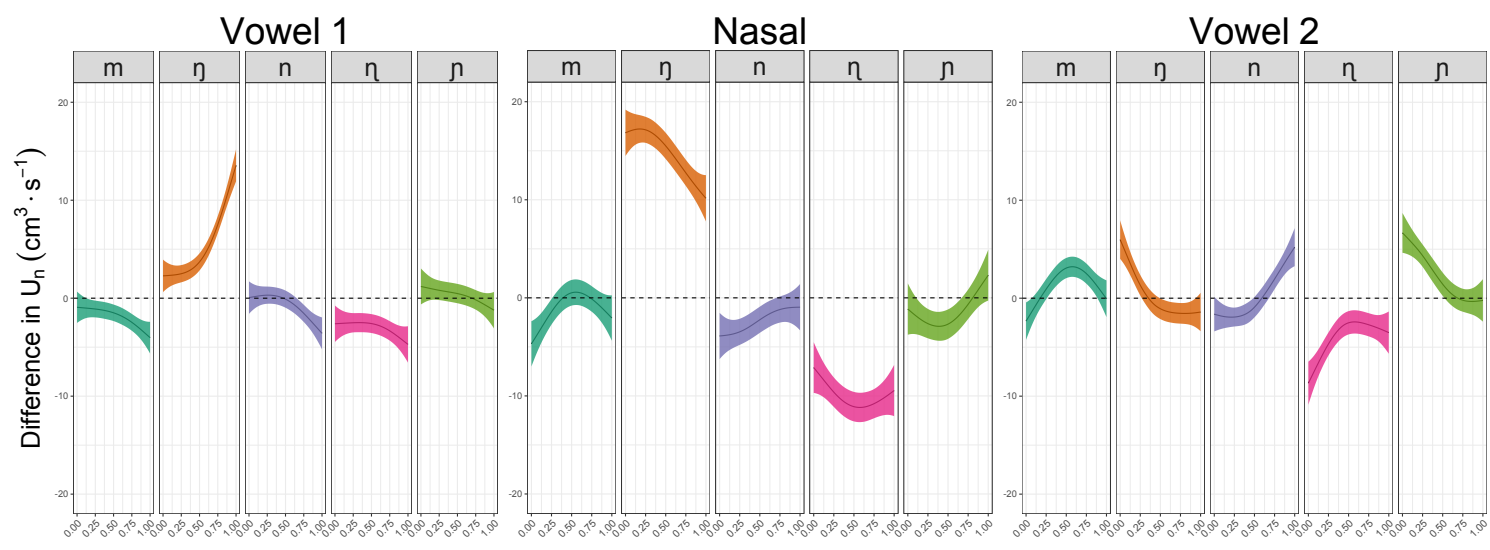

Normalized Time

Figure 6. Interactions between peak flow and phonemes Vowel $\left(V_{1}\right)$, Nasal, Vowel $\left(V_{2}\right)$ sequences

In the pre-nasal vowel $V_{1}$ the velar nasal has a higher flow overall when compared with the other phonemes and that the difference begins at approximately $60 \%$ into $\mathrm{V}_{1}$. This increased flow for the velar is maintained within the nasal closure and into the final vowel. The bilabial nasal has a maximum peak nasal flow that is early when compared to the other nasals and the palatal nasal has a late peak of nasal flow. This interaction shows that the velar nasal is patterning separately in comparison to the other places of articulation. This confirms the results shown in Figure 5.

The SSANOVA analysis shows that the onset of the first rise in nasal airflow is toward the end of the vowel for all places of articulation. The plot does not adequately show the variation present in the sample in terms of the timing of the airflow maximum. As discussed in the method there is considerable variation in the amplitude of the signal across speakers. Utterances with higher overall amplitude may be contributing more to the shape of the plotted curve, despite the SSANOVA for each segment being calculated separately for Figures 5 and 6 above. In order to control for these differences in the amplitude of peak flow a further spline smoothing measurement has been applied and the entire sequence of Vowel, nasal, vowel has been 
registered in terms of oral closure in the nasal (Figure 7a) and proportional nasal maximum (Figure $7 \mathrm{~b})$. The $\mathrm{U}_{\mathrm{n}}$ channel is transformed into a proportional value $\left(\Delta \mathrm{U}_{\mathrm{n}}\right)$, with 0 set as the absolute minimum flow value for the sequence and 1 the absolute maximum. This measure does not look at the carryover condition. The vertical dashed line on each plot in Figure 7 illustrates the average moment of full oral closure in the nasal.
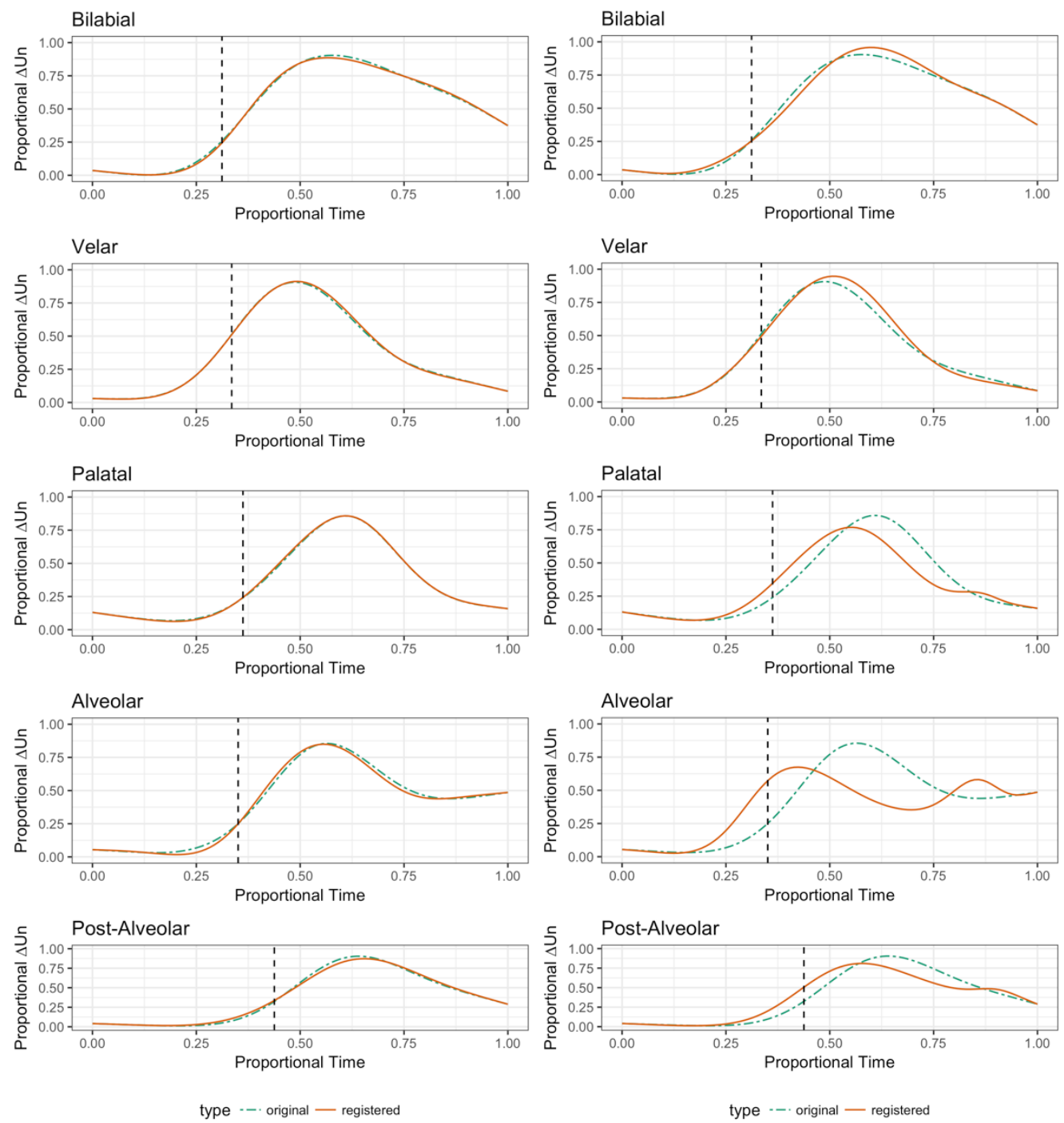

Figure 7. The left-hand figure (7a.) show the proportional change in nasal airflow ( $\Delta U n)$ registered by oral closure in the nasal and the right-hand figure ( $7 b$.) $\Delta U n$ registered by maximum flow both over proportional time of an entire $V N V$ sequence. In each plot the dashed vertical line shows the average time of the onset of oral closure based on the acoustic signal. The dashed curve shows the unregistered Un signal.

Figure 8 shows the duration of each place of articulation in the aerodynamic analysis. The apical consonants are significantly shorter than the peripherals or laminals $(p<.001)$. When considered together with figure $7 \mathrm{~b}$ we see that for the apico-alveolar and apico-post-alveolar nasals there is a bimodal nasal maximum pattern which is evidence of the greater levels of 
prestopping at this place of articulation. The short duration of these articulations which also makes them harder to synchronize with the velum lowering gesture so they both anticipate and delay more than the other places of articulation. This information is not available in Figure 5 or 6 but the delay in airflow rise is clear in Figure 7 showing that while the SSANOVA can be very informative regarding timing it is influenced by domain of measurement and thus must be supported with further analyses.

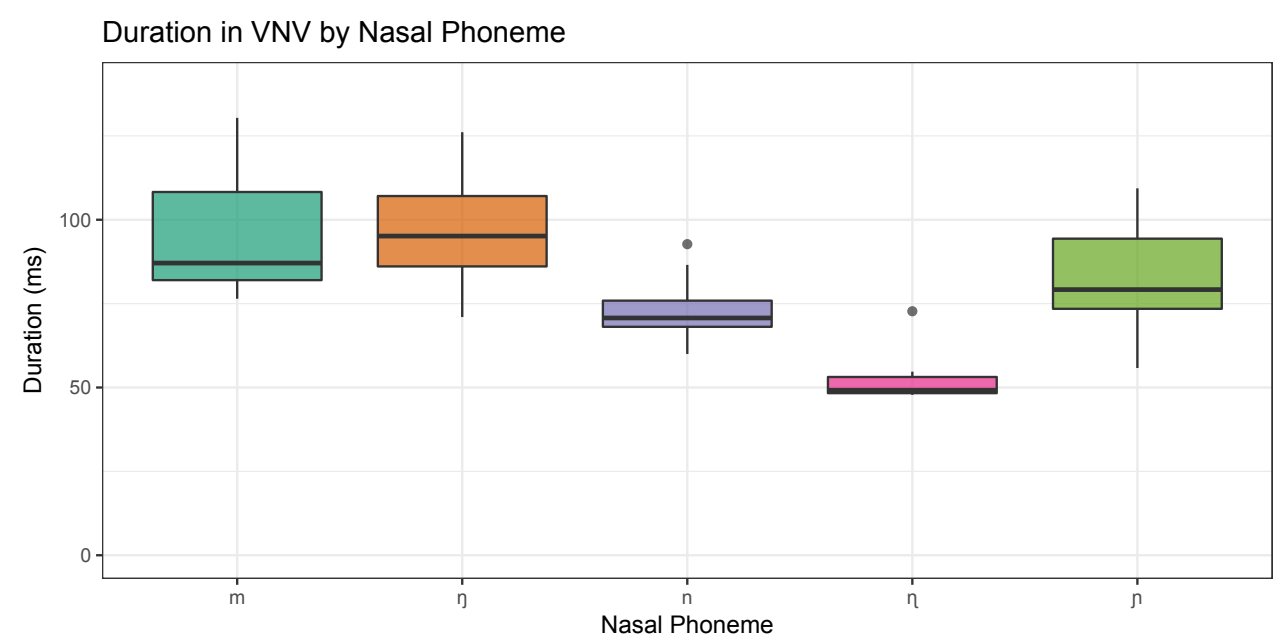

Figure 8. The duration of the intervocalic nasals in the aerodynamic subset separated by phoneme.

\section{Average nasal airflow in clusters}

Intervocalic singleton nasals are rare in $\mathrm{BKw}$ and nasals occurring in cluster environments are much more prevalent. To examine nasal articulation in clusters, word medial nasals preceded by a consonant between two vowels (VCNV) were measured (shown in Figures 9 and 10) as well as medial nasals followed by consonant between two vowels (VNCV) in shown in Figure 11 and Figure 12.

As with the intervocalic nasals shown in Figure 5, the dynamic averages of nasal flow are plotted in a/VNCV/sequence using an SSANOVA. This summarizes the three places of articulation, bilabial, apico-alveolar and dorso-velar found in in both heterorganic and homorganic clusters. As with the other non-nasal environments there is minimal anticipatory nasal airflow, although there is greater carry-over nasal flow in $\mathrm{V}_{2}$ which carries over into non-nasal vowel environments. 


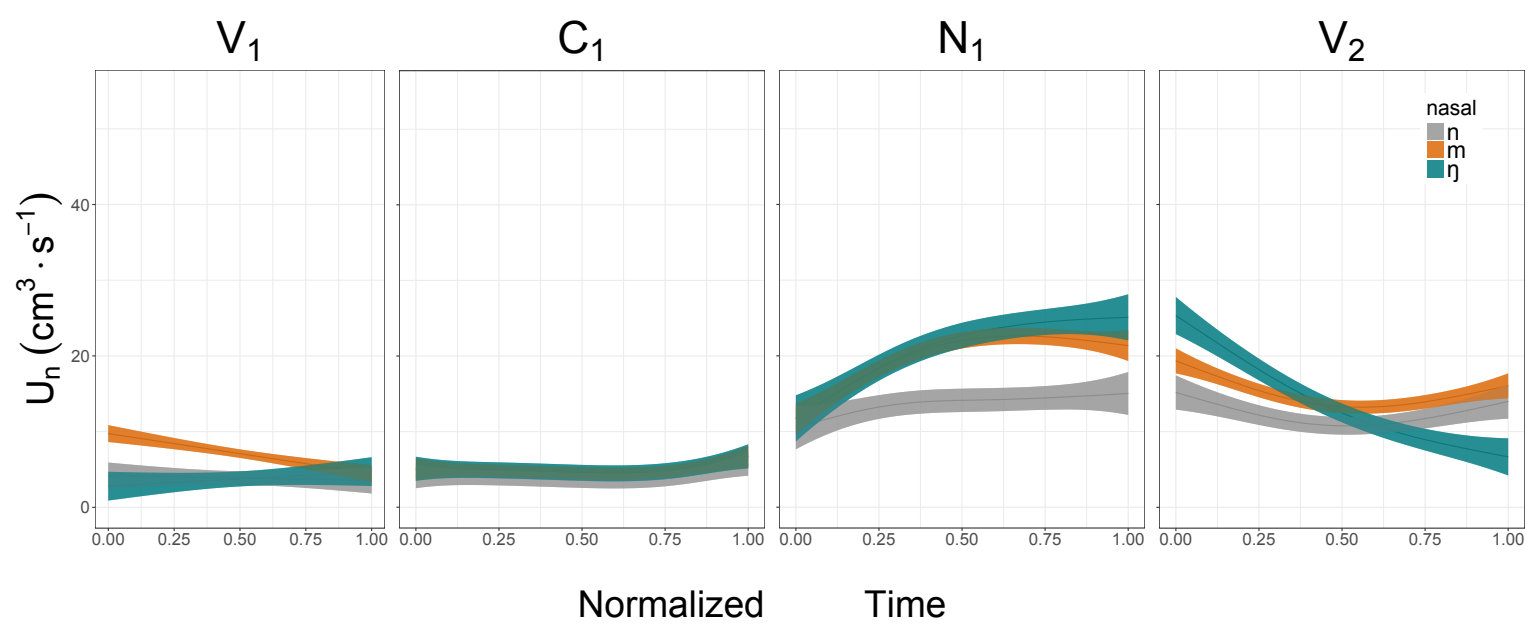

Figure 9. Airflow of bilabial nasals in time normalized Vowel, Oral Stop (C1) Nasal Stop (N1), Vowel sequences.

In VCNV environments the preceding stop is always voiceless with a long duration and nasal airflow increases just prior to the nasal onset (shown in Figure 9). The preceding voiceless consonant ensures that the velar port is closed and suppresses nasalization. The positive nasal flow in the sequence that includes the bilabial nasal $/ \mathrm{m} /$ is due to carryover nasalization from the nasal in the carrier phrase. This is due to the voiced initial post-alveolar lateral /// not interrupting voicing or carryover nasalization from the carrier phrase ['lopmen] (see the wordlist in Table 1. above).

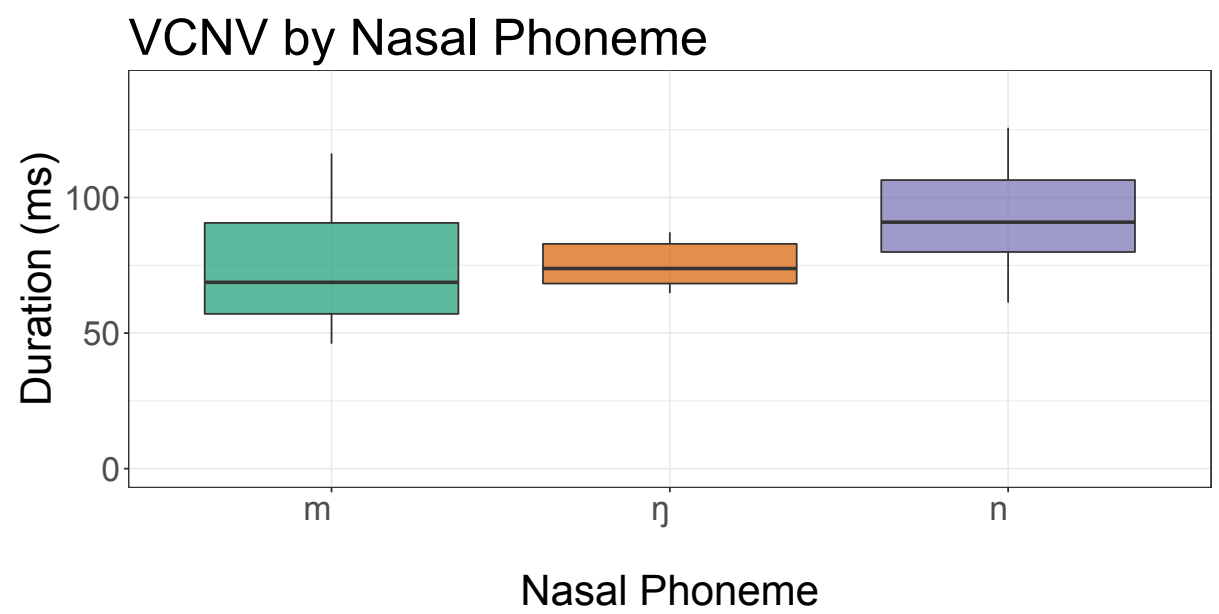

Figure 10 Duration of a nasal in VCNV sequence, separated by place of articulation

When the nasal is in the first position of the cluster the following consonants is invariably voiced and there is extensive carryover nasalization as shown in Figure 11. The positive nasal airflow in the token containing the apico-alveolar nasal $[\mathrm{n}]$ is from an initial $[\mathrm{m}]$ in the word [men'bender] which is in the prefix man-. There is considerable variation in the amount of nasalization in the $V_{2}$ position which confounds the SSANOVA measure which is mainly due to other nasal phonemes in the word. The durations shown in Figure 12 are marginally longer than 
those shown above in Figure 10. Notably the coronal consonants are much longer than they are in the singleton VNV environment.

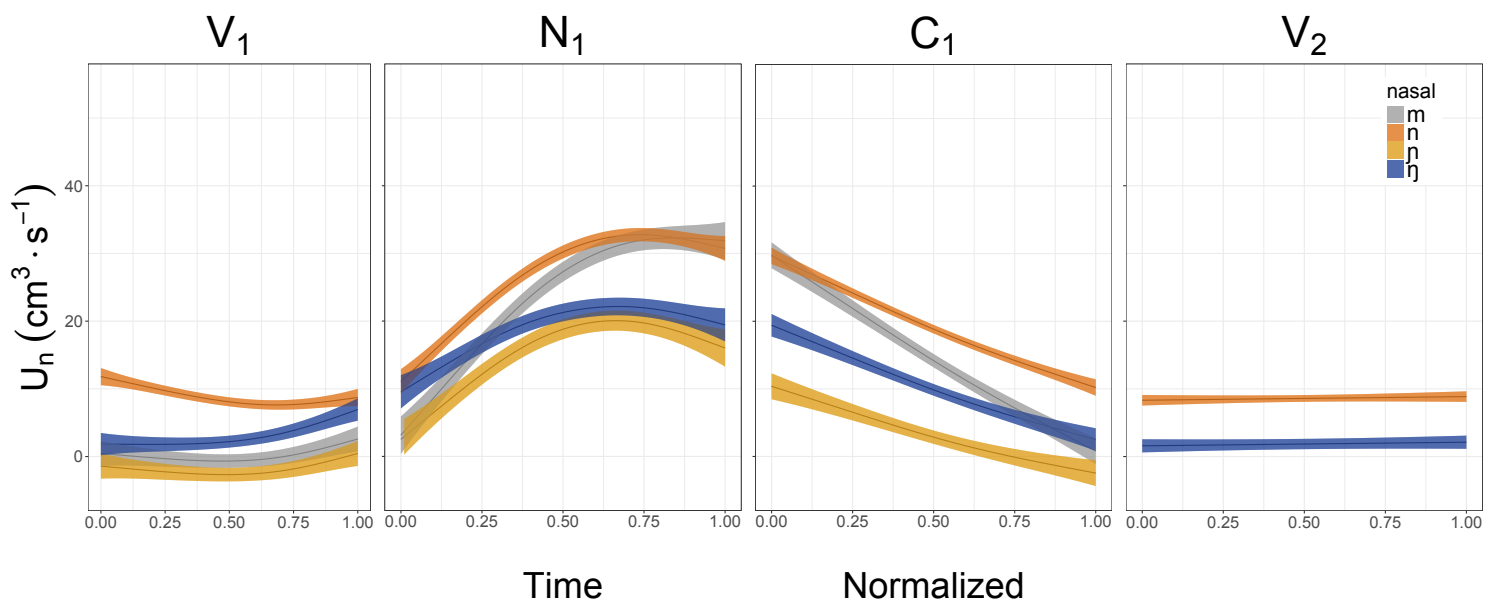

Figure 11. Airflow of bilabial nasals in time normalized Vowel, Oral Stop (C1) Nasal Stop (N1), Vowel sequences.

In addition to a longer duration, the nasal also has a higher magnitude signal than in the VCNV environment. This is significant for all places of articulation. This suggests that the $\mathrm{C}_{1} / \mathrm{N}_{1}$ (first) position of a cluster is strengthened in terms of manner of articulation cues and as this is the site of most phonological contrasts in the language, also indicates strengthening of place of articulation cues.

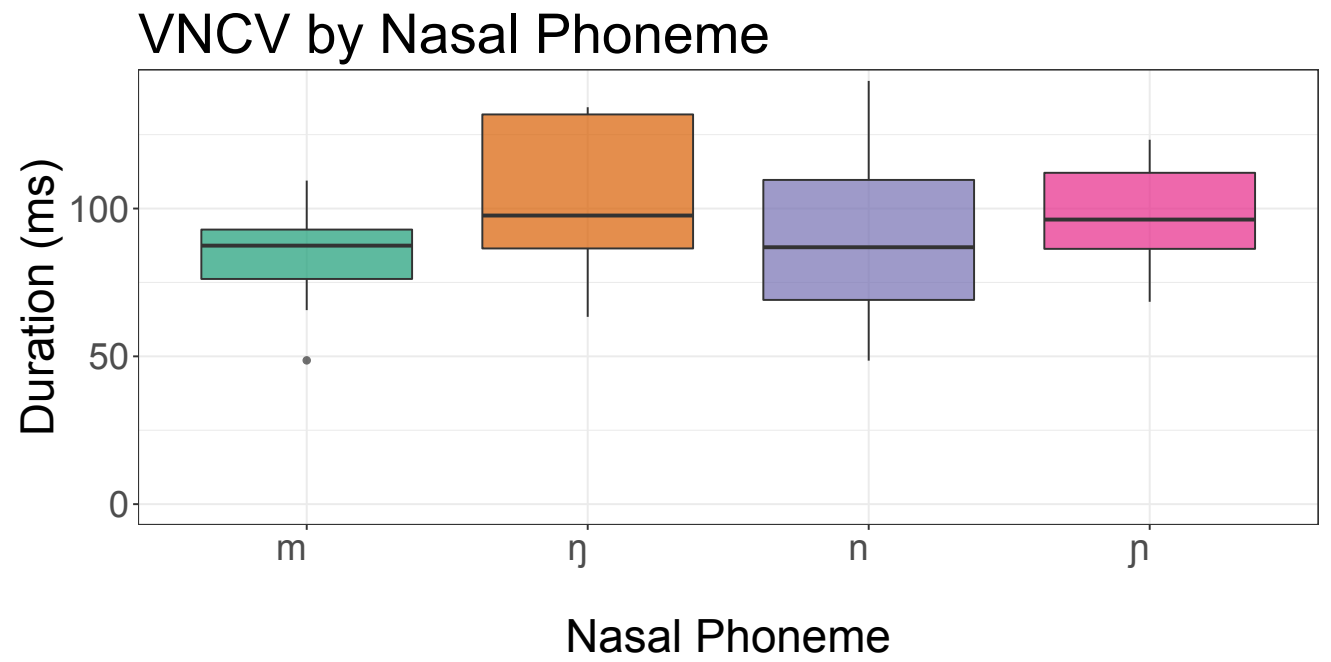

Figure 12. Duration of a nasal in VNCV sequence, separated by place of articulation

The consonants preceding a nasal in $\mathrm{VC}_{1} \mathrm{NV}$ sequences invariably voiceless and although the durations are not as long, they have many of the characteristics of fortis stops occurring in post-tonic, word medial positions (Stoakes, 2013). In $\mathrm{VN}_{1} \mathrm{CV}$ sequences the nasal is marginally longer for the coronal consonants $/ \mathrm{n} /$ and $/ \mathrm{n} /(\mathrm{p}<.01)$, longer for the velar $/ \mathrm{p} /(\mathrm{p}<.001)$ when compared with singleton consonants. The second consonant in the cluster is fully voiced and the nasalization is carried over into $\mathrm{V}_{2}$. 


\subsection{Discussion and Conclusions}

Phonetically, Bininj Kunwok speakers use language specific strategies in order to limit anticipatory nasalization in prosodically prominent positions, a pattern of coarticulatory resistance thought to be common across Australian languages (after Butcher 2006). By reducing the nasalization in the preceding vowel, the transitional place of articulation information can be enhanced allowing many places of articulation to remain contrastive.

In $\mathrm{BKw}$, peak nasal airflow measurements show very little anticipatory flow in vowels preceding a word medial nasal and these air flow patterns suggest that there is a delay in full velum lowering until after oral closure in a nasal phoneme articulation and that this sometimes results in prestopping particularly for an apical-alveolar nasal. The nasalization patterns in each of these environments suggest that there is a process of contrast enhancement and coarticulatory resistance in these prosodically prominent $\mathrm{VN}$ and $\mathrm{VNC}$ sequences.

Broadly the results are similar to those observed in phonologically non-nasalized vowels preceding nasals in French where vowels are produced with less nasal airflow in order to avoid perceptual confusion with phonemically nasal vowels. It should be noted that there is also an interaction with vowel height (Delvaux et al., 2008). In BKw, a similar effect is found at the onset of intervocalic singleton nasals and in clusters of nasal plus stop. These patterns also accord with Beddor's (2009) finding that there is an inverse relationship between nasal duration and peak flow although the latter was only observed in nasal codas. What is clear from these results is that the observed patterns are found regardless of the syllable affiliation of the nasal.

The presence of nasalization in the carryover context shows that rather than simply compressing or speeding up the velum-lowering gesture, the entire gesture is delayed, as evidenced by the patterns shown in Figures $7 \mathrm{a}$ and $7 \mathrm{~b}$. The temporal delay of a velum raising gesture causes significant nasal airflow to be present in the post-nasal vowel and as there is no phonological nasalization contrast in vowels the nasalization is not fully stopped until a following voiceless (non-sonorant) consonant. If the following consonant is also a nasal the velum will remain open throughout the vowel.

When examining the timing of peak of nasalization, coronal nasals (apico-alveolars and apicopost-alveolars) have a peak in nasalization that is synchronous with the offset of oral closure which is possibly due to the short duration at this place of articulation in intervocalic nasals. The laminal nasal $/ \mathrm{n} /$ has a more delayed peak of nasalization with respect to the onset of oral closure 
(Figure 7a). The velar nasal shows an increased nasal airflow starting after $50 \%$ of the initial vowel $\left(\mathrm{V}_{1}\right)$ and reaches its peak of earlier than the other nasals. The coronal and laminal consonants have their maximum peak of nasalisation at the acoustic offset of the nasal (centre panel of figure 5). Figure 6 . shows that for velars $(/ \mathrm{y} /)$ the difference in flow is greater in $\mathrm{V}_{1}$ and $\mathrm{N}$ than the other phonemes. The palatal $(/ \mathrm{n} /)$ has a marginally higher peak flow at the onset of the second vowel $\left(\mathrm{V}_{2}\right)$ indicating that it has the highest carryover nasalisation although this effect is not seen in figure $7 \mathrm{a}$ when the entire sequence is normalized. This carryover effect may be due to the greater contact area of the laminal articulator meaning that coordination between oral closure and nasalisation is more difficult to maintain. In velars, velum lowering is less delayed because, unlike with coronal articulations, the velum may need to be lowered to make a tight closure with the tongue dorsum within the articulation. Following on from this, the velar is the only place of articulation that shows consistent anticipation of nasalization in the preceding vowel. In each of the aerodynamic analyses, the velar place of articulation has a higher overall flow that is anticipated in the preceding consonant. Word initial velar nasals are highly unstable in $\mathrm{BKw}$ and are the segment most likely undergo significant lenition in word initial position particularly when preceding a low vowel. These positions are prefixing morphemes which are common and lexically predictable. In order to investigate the interaction between vowel quality (height), morphological structure and prosodic position in $\mathrm{BKw}$ and beyond, further research is required which control for these variables.

Despite the large proportion of sonorant segments in the language, intervocalic nasals are rare in the language. A natural utterance may contain many word medial clusters often straddling morpheme boundaries, with each member of the cluster possibly associating with a different syllable. This cluster environment provides many interesting durational and coarticulation patterns. To summarize, duration is greater in the first $\mathrm{C}_{1} / \mathrm{N}_{1}$ position of a cluster for both oral stops and nasals. As outlined above, we observe a delay in the nasal gesture inferred from the nasal airflow patterns. In other words, in word medial clusters the $\mathrm{C}_{1}$ position shows articulatory strengthening in both plosives and nasals which is manifest in consonant lengthening. The results presented in this study also suggest that the entire nasal gesture is delayed relative to the oral closure phase in $\mathrm{VN}$ sequences.

One consequence of this delay, particularly when the velum is lowered very late in a nasal phoneme, is a gap in the speech stream occurring after oral closure which results in an epenthetic oral stop. These articulations are commonly termed pre-stops and as mentioned above are very similar phonetically to the post-ploded nasals found in some Austronesian languages Cohn and Riehl (2008). This is a process is widespread for nasals and laterals in Australian languages 
(Butcher \& Loakes, 2008; Maddieson \& Ladefoged, 1993; Harvey, Lin, Turpin, Davies, \& Demuth, 2015; Hercus, 1972, 1994; Loakes, Butcher, Fletcher, \& Stoakes, 2008) and is present phonetically in BKw (Stoakes, 2013), Warlpiri (Fletcher et al., 2009) and Kaytetye (Harvey et al., 2015). In Eastern and Central Arrernte languages, the prevalence and consistency of prestopped articulations gives them phonemic status (Breen \& Pensalfini, 1999), although there is significant inter-speaker variation. The majority of Australian languages however, do not have phonologically pre-stopped nasals despite significant delays in velar port opening. Importantly for this analysis, pre-stopping is not phonological in BKw, and there has been no suggestion in various grammars of the language that this pattern is linguistically important to a speaker of the language (Carroll, 1976; Evans, 2003a; Harris, 1969; Oates, 1964; Stoakes, 2013). Also, there is no break in voicing in these stops so prestops does not interrupt pitch the excursion from a vowel into a nasal.

The coronal places of articulation (the apico-alveolar and apico-post-alveolar) have the greatest tendency to delay velum opening until after oral closure resulting in prestopping and the airflow patterns shown in Figure 7b. (right figure) show two peaks in the registered curves suggesting that the entire gesture is delayed. The alveolar nasals are generally relatively short and the tongue gesture in nasals described as a tap-like gesture. The apico-alveolar tap [ $\mathrm{r}$ ] is a common allophone of the stop [t/d] and the retroflex (post-alveolar) flap $[\mathrm{r}]$ is an allophone of the stop [t/d]. Although the oral gesture is quite short at these places of articulation, in the nasal articulations the whole velum opening gesture is delayed rather than being compressed so there is considerable carryover coarticulation.

In summary, the results of this study indicate that for a word containing an initial non-nasal the velar port is tightly closed until the just before or slightly after the oral closure in a following nasal. This allows phonetic prestopping at certain places of articulation which is in some languages is extreme enough to become phonologized.

Tight temporal control of velum lowering ensures place of articulation information is phonetically retrievable in an intervocalic environment. As mentioned above, consonants in the post-tonic intervocalic position are sites for the majority place of articulation distinctions, so it is imperative to prevent masking of the phonetic cues (Butcher, 2006).

We find a contrast enhancement in this environment in BKw and as argued earlier this is a site of prosodic enhancement (e.g. Fletcher, Stoakes, Loakes \& Singer, 2015). In sum, these findings also show a link between patterns of coarticulatory resistance and prosodic prominence in ' $\mathrm{V}-\mathrm{N}$ sequences, suggesting that speakers exert explicit control over the vowel nasalization process by delaying the velum lowering gesture so that there is no anticipatory nasalization in 
the accented vowel. Similar to findings by Cho, et al. (2017) in English, prosodic position thus effects the degree of nasalization with enhancement of the orality of the vowel preceding a nasal and enhancement of the consoantality of the nasal although this does not reduce the sonorance.

Anticipatory coarticulation is very tightly controlled in the production of BKw nasals which serves to enhance the place of articulation cues in consonants and possibly to improve overall contrastiveness for phonemes in prosodically prominent positions within a word. This occurs in the "post-tonic" position, associated with a preceding high pitch accent which can extend across sonorant phones into a syllable coda. In Lakota, Scarborough et. al, (2015) find that degree of coarticulation is strongly dependent on maintaining paradigmatic phonological contrast and that differences in the nasal patterns are not evidence of a language specific constraint on coarticulation, but instead, a contrast in vowels is “...enhanced to overcome, or to coexist with, coarticulation" (Scarborough et. al, 2015:306). In BKw the resistance to nasal coarticulation may primarily be in order to enhance place of articulation information in this highly phonologically contrastive position. This syntagmatic contrast between adjacent phones is restricted to the "posttonic" prosodic position suggesting that paradigmatic contrasts are used together with syntagmatic contrasts to enhance language comprehensibility. The tight control of anticipatory nasal coarticulation may serve to give us insight into some of the mechanisms the led to the stability of phoneme inventories in Australian languages over possibly vast time scales.

\section{Acknowledgements:}

We would like to thank first and foremost the participants in this study and all of the residents of Mamardawerre outstation for their patience and participation. Thanks to the editor Amalia Arvaniti, three anonymous reviewers, Debbie Loakes, Rosey Billington and the Postdoc Reading Group at The University of Melbourne, all errors remain our own. Thanks also to Nick Evans Murray Garde for assistance in the early stages of this project. Funding was provided by the ARC Discovery Project DP0557540 and the Centre of Excellence for the Dynamics of Language CoE14010004. 


\section{References:}

Al-Bamerni, Ameen H. A. 1983. Oral, velic and laryngeal coarticulation across languages, Unpublished Thesis (D Phil ). University of Oxford.

Baayen, R. Harald, Douglas J. Davidson, \& Douglas M. Bates. 2008. Mixed-effects modeling with crossed random effects for subjects and items. Journal of Memory and Language, 59(4), 390-412.

Baken, R.J., \& R.F. Orlikoff. 2000. Clinical measurement of speech and voice (2nd ed.). Singular Publishing Group.

Basset, Patricia, Angélique Amelot, Jacqueline Vaissière, \& Bernard Roubeau. 2002. Nasal airflow in French spontaneous speech. Journal of the International Phonetic Association, 31(1), 87-99.

Bates, Douglas, Martin Maechler, \& Ben Bolker. 2011. 1me4: Linear mixed-effects models using S4 classes [Computer software manual]. (R package version 0.999375-42).

Beddor, Patrice Speeter. 2009. A coarticulatory path to sound change. Language, 85(4), 785821.

Beddor, Patrice Speeter, \& Rena A. Krakow. 1999. Perception of coarticulatory nasalization by speakers of English and Thai: Evidence for partial compensation. The Journal of the Acoustical Society of America, 106(5), 2868-2887.

Beddor, Patrice Speeter, Kevin B. McGowan, Julie E. Boland, Andries W. Coetzee \& Anthony Brasher. 2013. The time course of perception of coarticulation. The Journal of the Acoustical Society of America, 133(4), 2350-2366.

Bell-Berti, Fredericka. 1993. Understanding velic motor control: studies of segmental context. In Marie K. Huffman \& Rena A. Krakow (Eds.), Nasals, nasalization and the velum (Vol. 5.). San Diego: Academic Press, 63-85.

Bell-Berti, Fredericka, Rena A. Krakow, \& Dorothy Ross. 1993. Velar coarticulation revisited (A). The Journal of the Acoustical Society of America, 94(3), 1881.

Benguerel, A-P, \& Helen A. Cowan. 1974. Coarticulation of upper lip protrusion in French. Phonetica, 30(1), 41-55.

Benkí, José Ramon. 2003. Analysis of English nonsense syllable recognition in noise. Phonetica, 60(2), 129-157.

Billington, Rosey. 2014. 'Advanced tongue root' in Lopit: Acoustic and ultrasound evidence. In Jennifer Hay \& Emma Parnell (Eds.), Proceedings of the 15th Australasian International Speech Science and Technology conference. Christchurch, New Zealand: ASSTA. 119-122.

Bishop, Judith. and Janet Fletcher. (2005). Intonation in six dialects of Bininj Gun-Wok. In Sun-Ah Jun, (Ed.), Prosody and typology - a unified approach. Oxford University Press, Oxford. 331-361.

Bladon, R. Anthony, \& Ameen Al-Bamerni. 1982. One stage and two-stage temporal patterns of velar coarticulation (A). The Journal of the Acoustical Society of America, 72, S104.

Blevins, Juliette. 2001. Where have all the onsets gone? Initial consonant loss in Australian Aboriginal languages. In Jane Simpson, David Nash, Mary Laughren, Peter Austin, \& Barry Alpher (Eds.), Forty years on: Ken Hale and Australian languages (chap. 35). Canberra: Pacific Linguistics, Australian National University. 481-492. 
Boersma, Paul, \& David Weenink. 2015. Praat: Doing phonetics by computer [computer program]. The University of Amsterdam. (retrieved: 05/06/2017 from http://www.praat.org, Version: 6.0.29).

Breen, Gavan, \& Rob Pensalfini. 1999. Arrernte: a language with no syllable onsets. Linguistic Inquiry, 30(1), 1-25.

Butcher, Andrew. R. 1994. On the phonetics of small vowel systems: evidence from Australian languages. In R. Togneri, editor, 5th Australian International Conference on Speech Science and Technology, volume 1, pages 28-33, Canberra. Australian Speech Science and Technology Association.

Butcher, Andrew. 1996. Some connected speech phenomena in Australian languages: universals and idiosyncrasies. In Adrian P. Simpson, \& M. Pätzold, (eds) Sound Patterns of Connected Speech: Description, Models and Explanation. Proceedings of the symposium held at Kiel University on 14-15 June 1996 (Arbeitsberichte 31, Institut für Phonetik der Universität Kiel), 83-10.

Butcher, Andrew R. 1999. What speakers of Australian Aboriginal languages do with their velums and why: The phonetics of the nasal/oral contrast. In J. J. Ohala, Y Hasegawa, D. Granville, \& A. C Bailey (Eds.), The Proc. XIVth international Congress of Phonetic Science. San Francisco, USA. 479-482.

Butcher, Andrew R. 2006. Consonant-salient phonologies and the 'place-of-articulation imperative'. In Jonathan Harrington \& Marija Tabain (Eds.), Speech production: Models, phonetic processes and techniques. New York: Psychology Press. 187-210.

Butcher, Andrew R, \& Deborah E. Loakes. 2008. Enhancing the left edge: The phonetics of prestopped sonorants in Australian languages. The Journal of the Acoustical Society of America, 124(4), 2527-2527.

Carignan, Christopher. 2017. Covariation of nasalization, tongue height, and breathiness in the realization of F1 of Southern French nasal vowels. Journal of Phonetics, 63, 87-105.

Carroll, Peter. 1976. Kunwinjku (Gunwinggu): A language of Western Arnhem Land (Unpublished Masters Thesis). Australian National University, Canberra.

Chafcouloff, Michel, \& A. Marchal. 1999. Velopharyngeal coarticulation. In William J. Hardcastle \& Nigel Hewlett (Eds.), Coarticulation: Theory, data and techniques. Cambridge, UK: Cambridge University Press. 69-79.

Chen, Marilyn Y. 1997. Acoustic correlates of English and French nasalized vowels. The Journal of the Acoustical Society of America, 102(4), 2360-2370.

Cho, T. (2001). The effects of prosody on articulation in English. Unpublished $\mathrm{PhD}$ Thesis, Linguistics, UCLA.

Cho, Taehong. and Sun-Ah Jun. (2000). Domain initial strengthening as enhancement of laryngeal features: Aerodynamic evidence from Korean. In Okrent, A. and Boyle, J. P., editors, Proceedings of the Chicago Linguistics Society, 36(1), 57-69.

Cho, Taehong, Daejin Kim, \& Sahyang Kim. 2017. Prosodically-conditioned fine-tuning of coarticulatory vowel nasalization in English. Journal of Phonetics, 64, 71-89.

Clark, H.H. 1973. The language-as-fixed-effect fallacy: A critique of language statistics in psychological research. Journal of verbal learning and verbal behavior, 12(4), 335-359.

Clumeck, Harold. 1976. Patterns of soft palate movements in six languages. Journal of Phonetics, 4(4), 337-351.

Cohn, Abigail C, \& Anastasia K. Riehl. 2008. The internal structure of nasal-stop sequences: 
Evidence from Austronesian. In Paul Warren (Ed.), The proceedings of Laboratory Phonology 11, Wellington, New Zealand (Vol. 11).

Crowley, Terry, 1981. The Mpakwithi dialect of Anguthimri. In: R.M.W Dixon. \& B.J. Blake, (Eds.) Handbook of Australian Languages Vol. 2. Canberra: ANU Press, 146-194.

Davidson, Lisa. 2006. Comparing tongue shapes from ultrasound imaging using smoothing spline analysis of variance. The Journal of the Acoustical Society of America, 120(1), 407-415.

Delvaux, Veronique, Didier Demolin, Bernard Harmegnies, \& Alain Soquet, 2008. The aerodynamics of nasalization in French. Journal of Phonetics, 36(4), 578-606.

Dixit, R. Prakash, \& Peter F. MacNeilage, 1972. Coarticulation of nasality: Evidence from Hindi (A). The Journal of the Acoustical Society of America, 52(1A), 131-132.

Dixon, Robert M. W. 1980. The Languages of Australia. Cambridge, Eng.; New York: Cambridge University Press.

Docherty, Gerard, Simón Gonzalez, \& Nathaniel Mitchell. 2015. Static vs. dynamic perspectives on the realization of vowel nucleii in West Australian English. In the Scottish Consortium for ICPhS, 2015 (Ed.), Proceedings of the 18th international congress of phonetic sciences. Glasgow, Scotland.

Etherington, Steven, \& Narelle Etherington, 1998. Kunwinjku Kunwok: A short introduction to Kunwinjku language and society (3rd ed.). Kunbarllanjnja: The Kunwinjku Language Centre.

Evans, Nicholas. 1995. Current Issues in Australian phonology. In John Goldsmith, (Ed.), Handbook of Phonological Theory. Oxford: Blackwells. 723-761.

Evans, Nicholas. 2003a. Bininj Gun-Wok: a pan-dialectal grammar of Mayali, Kunwinjku and Kune (No. 541). Canberra: Pacific Linguistics, Research School of Pacific and Asian Studies, Australian National University.

Evans, Nicholas. 2003b. The Non-Pama-Nyungan languages of Northern Australia: comparative studies of the continent's most linguistically complex region. Canberra: Pacific Linguistics.

Farnetani, Edda, \& Shiro Kori, 1986. Effects of syllable and word structure on segmental durations in spoken Italian. Speech communication, 5(1), 17-34.

Farnetani, Edda. and D. Recasens. 1999. Coarticulation models in recent speech production theories. In W. J. Hardcastle, and Nigel. Hewlett, editors, Coarticulation: theory, data and techniques, Cambridge: Cambridge University Press. 31-65.

Farnetani, Edda. and D. Recasens, 2013. Coarticulation and connected speech processes. In William J. Hardcastle, John Laver, \& Fiona E. Gibbon (Eds.), The Handbook of Phonetic Sciences, volume 79. Chichester: Wiley-Blackwell. 316-352.

Flege, James Emil. 1988. Anticipatory and carry-over nasal coarticulation in the speech of children and adults. Journal of Speech and Hearing Research, 31(4), 525-536.

Fletcher, Janet. M. and Andrew R. Butcher. 2002. Vowel dispersion in two Northern Australian languages: Dalabon and Bininj Gun-Wok. In Cathy Bow (Ed.), Proceedings of the 9th Australian International Conference on Speech Science and Technology, Melbourne: Australian Speech Science and Technology Association Inc. 343-348.

Fletcher, Janet M., \& Andrew R. Butcher. 2014. Sound patterns of Australian languages. In Harold Koch \& Rachel Nordlinger (Eds.), The languages and linguistics of Australia: A comprehensive guide, (Chap. 2), 91-138. Walter de Gruyter, Berlin. 
Fletcher, Janet M., Andrew R. Butcher, Deborah E. Loakes, \& Hywel M. Stoakes. 2010. Aspects of nasal realization and the place of articulation imperative in Bininj Gun-wok. In Marija Tabain, Janet M. Fletcher, David Grayden, John Hajek, \& Andrew R. Butcher (Eds.), Proceedings of the 13th Australian International Conference on Speech Science and Technology. Melbourne, Australia: ASSTA, Inc. 78-81.

Fletcher, Janet M., Andrew R. Butcher, Deborah E. Loakes, \& Hywel M. Stoakes. 2011. Coarticulation and consonant cluster production in Iwaidja. The Journal of the Acoustical Society of America, 129(4), 2452-2452.

Fletcher, Janet M., Deborah E. Loakes, \& Andrew R. Butcher. 2009. Coarticulation in nasal and lateral clusters in Warlpiri. In Annual conference, international speech communication association (1st ed., Vol. 1), 86-89.

Fletcher, Janet M., Hywel M. Stoakes, Deborah E. Loakes, \& Andrew R. Butcher,.2007. Spectral and durational properties of vowels in Kunwinjku. In Proceedings of the 16th international congress of the phonetic sciences. Saarbrücken. 937-940.

Fletcher, Janet M., Hywel M. Stoakes, Deborah E. Loakes, and Ruth Singer. 2015. Accentual prominence and consonant lengthening and strengthening in Mawng. In the Proceedings of ICPhS 2015, The Scottish Consortium for ICPhS 2015 (Eds.), London: International Phonetic Association.

Fletcher, Janet, Hywel M. Stoakes, Ruth Singer, \& Deborah E. Loakes. 2016. Intonational correlates of subject and object realisation in Mawng (Australian). Speech Prosody 2016, 188-192.

Fougeron, Cecile, \& Patricia A. Keating. 1997. Articulatory strengthening at edges of prosodic domains. The Journal of the Acoustical Society of America, 101(6), 3728-3740.

Fougeron, C. (2001). Articulatory properties of initial segments in several prosodic constituents in French. Journal of Phonetics, 29(2):109-135.

Fowler, Carol A, \& Julie M. Brown. 2000. Perceptual parsing of acoustic consequences of velum lowering from information for vowels. Perception \& Psychophysics, 62(1), 2132 .

Fruehwald, Josef. 2017. Generations, lifespans, and the zeitgeist. Language Variation and Change, 29(1), 1-27. doi: 10.1017/S0954394517000060

Garde, Murray. in prep. Bininj Kunwok Dictionary. ANU.

$\mathrm{Gu}$, Chong. 1990. Adaptive spline smoothing in non-Gaussian regression models. Journal of the American Statistical Association, 85(411), 801-807.

Gu, Chong. 2014. Smoothing spline ANOVA models: R package gss. Journal of Statistical Software, 58(5), 1-25. Retrieved from http://www.jstatsoft.org/v58/i05/

Haddican, Bill, Paul Foulkes, Vincent Hughes, \& Hazel Richards. 2013. Interaction of social and linguistic constraints on two vowel changes in northern England. Language Variation and Change, 25(03), 371-403.

Hajek, John. 1997. Universals of sound change in nasalization. Oxford, UK; Boston: Blackwell Publishers.

Hamilton, P. J. 1996. Phonetic constraints and markedness in the phonotactics of Australian Aboriginal languages ( $\mathrm{PhD}$ Thesis). University of Toronto.

Harrington, Jonathan. 1994. The contribution of the murmur and vowel to the place of articulation distinction in nasal consonants. The Journal of the Acoustical Society of America, 96(1), 19-32. 
Harrington, Jonathan. 2012. Acoustic phonetics. In William J. Hardcastle, John Laver, \& Fiona E. Gibbon (Eds.), The Handbook of Phonetic Sciences (2nd ed., Vol. 79). WileyBlackwell. 81

Harrington, Jonathan, Felicitas Kleber, \& Ulrich Reubold. 2013. The effect of prosodic weakening on the production and perception of trans-consonantal vowel coarticulation in German. The Journal of the Acoustical Society of America, 134(1), 551-561.

Harrington, Jonathan. and Florian Schiel. 2017. /u/-fronting and agent-based modeling: The relationship between the origin and spread of sound change. Language, 93(2):414-445.

Harris, Joy Kinslow. 1969. Descriptive and comparative study of the Gunwingguan languages, Northern Territory ( $\mathrm{PhD}$ Thesis). Australian National University.

Harvey, Mark, Susan Lin, Myfany Turpin, Ben Davies, \& Katherine Demuth. 2015. Contrastive and non-contrastive pre-stopping in Kaytetye. Australian Journal of Linguistics, 35(3), 232-250.

Harvey, Mark, and Robert Mailhammer. 2018. Reconstructing remote relation- ships ProtoAustralian noun class prefixation. Diachronica, 34(4):470-515.

Hercus, Luise A. 1972. The pre-stopped nasal and lateral consonants of Arabana-Wangayuru. Anthropological Linguistics, 14(8), 293-305.

Hercus, Luise A. 1994. A grammar of the Arabana-Wangkangurru language: Lake Eyre Basin, South Australia. Canberra: Research School of Pacific and Asian Studies, Australian National University.

Heyne, Matthias, \& Donald Derrick. 2015. Using a radial ultrasound probes virtual origin to compute midsagittal smoothing splines in polar coordinates. The Journal of the Acoustical Society of America, 138(6), EL509-EL514.

Huffman, M. (1988). Timing of contextual nasalization in two languages. UCLA - Working Papers in Phonetics, 69: 68-76.

Keating, Patricia, Taehong Cho, Cécile Fougeron, \& Chai-Shune Hsu. 1998. Domain-initial articulatory strengthening in four languages. In Papers in laboratory phonology VI. John Local, Richard Ogden, Rosalind Temple. (Eds.). Cambridge: Cambridge University Press. 143-161.

Kirkham, Sam. 2017. Ethnicity and phonetic variation in Sheffield English liquids. Journal of the International Phonetic Association, 47(1), 17-35.

Koch, Harold. 2014. Historical relations among the Australian languages: Genetic classification and contact-based diffusion. In Harold Koch \& Rachel Nordlinger (Eds.), The languages and linguistics of Australia: A comprehensive guide, (Chap. 2), 23-89. Walter de Gruyter, Berlin.

Krakow, Rena Arens. 1999. Physiological organization of syllables: a review. Journal of Phonetics, 27(1), 23-54.

Krakow, Rena A. and Marie K. Huffman. 1993. Instruments and techniques for investigating nasalization and velopharyngeal function in the laboratory: an introduction. In M. K. Huffman, and R. A. Krakow, (Eds.), Nasals, Nasalization and the Velum, Academic Press: San Diego. 3-59.

Ladefoged, Peter. 2003. Phonetic data analysis: An introduction to fieldwork and instrumental techniques. Malden: Blackwell Publishing.

Lindblom, B. and Ian Maddieson. 1988. Phonetic universals in consonant systems. In Larry M. Hyman, \& C.N. Li, (Eds.) Language, Speech and Mind. Studies in honour of Victoria 
A. Fromkin. London/New York: Routledge, 62-78.

Loakes, Deborah E., Andrew R. Butcher, Janet M. Fletcher, \& Hywel M. Stoakes. 2008. Phonetically prestopped laterals in Australian Languages: A preliminary investigation of Warlpiri. In INTERSPEECH 2008, 9th Annual Conference of the International Speech Communication Association, Brisbane, Australia, September 22-26. 90-93.

Maddieson, Ian. 1988. Prenasalized stops and speech timing (A). The Journal of the Acoustical Society of America, 83, S28.

Maddieson, Ian. 1989. Prenasalized stops and speech timing. Journal of the International Phonetic Association, 19(2), 57-66.

Maddieson, Ian, \& Peter Ladefoged. 1993. Phonetics of partially nasal consonants. In Marie K. Huffman \& Rena A. Krakow (Eds.), Nasals, nasalization and the velum (Vol. 5). San Diego: Academic Press. 251-301.

Manakgu, Andrew, \& Steve Etherington. 1996. Basic Kunwinjku dictionary: A simplified English-Kunwinjku and Kunwinjku-English dictionary with semantic domain listing. The Kunwinjku Language Centre.

Manuel, Sharon Y. 1990. The role of contrast in limiting vowel-to-vowel coarticulation in different languages. The Journal of the Acoustical Society of America, 88(3), 1286-1298.

Mielke, Jeff. 2015. An ultrasound study of Canadian French rhotic vowels with polar smoothing spline comparisons. The Journal of the Acoustical Society of America, 137(5), 2858-2869.

Miller, George A., \& Patricia E. Nicely. 1955. An analysis of perceptual confusions among some English consonants. The Journal of the Acoustical Society of America, 27(2), 338.

Moll, Kenneth L., \& Raymond G. Daniloff. 1971. Investigation of the timing of velar movements during speech. The Journal of the Acoustical Society of America, 50(2B), 678-684.

Nycz, Jennifer, \& Paul. De Decker. 2006. A new way of analyzing vowels: comparing formant contours using smoothing spline ANOVA. In Poster presented at NWAV 35. Columbus Ohio, USA.

Oates, Lynette. F. 1964. A tentative description of the Gunwinggu language (of Western Arnhem Land). Oceania Linguistic Monographs, 10, 3-119.

O'Grady, G. N., C. F. Voegelin, \& F. M. Voegelin. 1966. Languages of the World: IndoPacific fascicle six. Anthropological Linguistics, 8(2) 1-197.

Ohala, John J. 1974. A mathematical model of speech aerodynamics. Proceedings of the Speech Communication Seminar, Stockholm (2) 65-72.

Ohala, John J. 1975. Phonetic explanations for nasal sound patterns. In Charles A. Ferguson, Larry M. Hyman, \& John J. Ohala (Eds.), Nasalfest: Papers from a symposium on nasals and nasalization 289-316 Stanford:

Ohala, John J. 1993. Coarticulation and phonology. Language and speech, 36(2-3), 155-170.

Pastore, Richard E, \& Shannon M. Farrington. 1996. Measuring the difference limen for identification of order of onset for complex auditory stimuli. Perception \& Psychophysics, 58(4), 510-526.

Pentland, Christina. 2004. Stress in Warlpiri: stress domains and word-level prosody, (Unpublished doctoral dissertation). The University of Queensland, School of English, Media Studies and Art History. 
Pierrehumbert, Janet. (1990). Phonological and phonetic representation. Journal of Phonetics, 18(3):375-394.

Pisoni, David B. 1977. Identification and discrimination of the relative onset time of two component tones: Implications for voicing perception in stops. The Journal of the Acoustical Society of America, 61(5), 1352-1361.

Proctor, Michael, Louis Goldstein., Adam Lammert, Dani Byrd, Asterios Toutios, Shrikanth Narayanan 2013. Velic coordination in French nasals: a real-time magnetic resonance imaging study. In the proceedings of INTERSPEECH 2013, Lyon, France, 577-581.

R Development Core Team. 2017. R: A language and environment for statistical computing [Computer software manual]. Vienna, Austria. (version 3.4.1). Retrieved from http://www.R-project.org (ISBN 3-900051-07-0).

Ramsay, J. O., H. Wickham, S. Graves, and G. Hooker. 2017. fda: Functional Data Analysis. $\mathrm{R}$ package version 2.4.7.

Recasens, Daniel. 1983. Place cues for nasal consonants with special reference to Catalan. Journal of the Acoustical Society of America, 73(4), 1346-1353.

Recasens, Daniel. 1989. Long range coarticulation effects for tongue dorsum contact in VCVCV sequences. Speech Communication, 8(4), 293-307.

Recasens, Daniel. 2004. The effect of syllable position on consonant reduction (evidence from Catalan consonant clusters). Journal of Phonetics, 32, 435-453.

Riehl, Anastasia K. 2008. The Phonology and Phonetics of Nasal Obstruent Sequences (Unpublished Thesis, PhD). Cornell University.

Riehl, Anastasia K, \& Abigail C. Cohn. 2011. Partially nasal segments. In Elizabeth Hume, Marc van Oostendorp, Colin J. Ewen \& Keren Rice (Eds.), The Blackwell Companion to Phonology. Blackwell Publishing Ltd.

Scarborough, Rebecca, Georgia Zellou, Armik Mirzayan, \& David S. Rood. 2015. Phonetic and phonological patterns of nasality in Lakota vowels. Journal of the International Phonetic Association, 45(3), 289-309.

Shosted, Ryan. 2003. Nasal coda restoration in Brazilian Portuguese. In Proceedings of the 15th international congress of phonetic sciences. Barcelona: Universitat autonoma.

Solé, Maria-Josep. 1992. Phonetic and phonological processes: The case of nasalization. Language and Speech, 35(1-2), 29-43.

Solé, Maria-Josep. 1995. Spatio-temporal patterns of velopharyngeal action in phonetic and phonological nasalization. Language and Speech, 38(1), 1-23.

Stevens, Kenneth N. 1998. Acoustic phonetics. Cambridge, Mass.: MIT Press.

Stoakes, Hywel M. 2013. An acoustic and aerodynamic analysis of consonant articulation in Bininj Gun-wok (Unpublished Thesis, PhD). The School of Languages and Linguistics, The University of Melbourne, Australia. http://hdl.handle.net/11343/42067.

Stoakes, Hywel M. 2016. Nasal aerodynamics and coarticulation in Bininj Kunwok: Smoothing spline analysis of variance. In Christopher Carignan \& Michael D. Tyler (Eds.), The proceedings of the sixteenth Australasian international conference on speech science and technology. Sydney, Australia.

Tabain, Marija, Andrew R. Butcher, Gavan Breen, \& Richard Beare. 2016. An acoustic study of nasal consonants in three Central Australian languages. The Journal of the Acoustical Society of America, 139(2), 890-903.

Whalen, Douglas H. 1990. Coarticulation is largely planned. Journal of Phonetics, 18, 3-35. 
Wickham, Hadley. 2009. ggplot2: Elegant graphics for data analysis. Springer Publishing. Winkelmann, Raphael, Klaus Jaensch, Steve Cassidy, \& Jonathan Harrington, 2017. emuR: Main package of the EMU speech database management system [Computer software manual]. (R package version 0.2.3)

Yanagihara, Naoaki, \& Charlene Hyde. 1966. An aerodynamic study of the articulatory mechanism in the production of bilabial stop consonants. Studia Phonologica, IV, 70-80.

Yiu, S.Y. 2015. Intonation of statements and question in Cantonese English: acoustic evidence from a smoothing spline analysis of variance. In the Scottish Consortium for ICPhS, 2015 (Eds.), The proceedings of the 18th international congress of phonetic sciences (ICPhS 2015). 


\section{University Library}

\section{- M M I N E R VA A gateway to Melbourne's research publications}

Minerva Access is the Institutional Repository of The University of Melbourne

Author/s:

Stoakes, HM;Fletcher, JM;Butcher, AR

Title:

Nasal coarticulation in Bininj Kunwok: An aerodynamic analysis

Date:

2020-12-01

Citation:

Stoakes, H. M., Fletcher, J. M. \& Butcher, A. R. (2020). Nasal coarticulation in Bininj

Kunwok: An aerodynamic analysis. Journal of the International Phonetic Association, 50 (3), pp.305-332. https://doi.org/10.1017/S0025100318000282.

Persistent Link:

http://hdl.handle.net/11343/258688 